Document downloaded from:

http://hdl.handle.net/10251/58490

This paper must be cited as:

Sans, J.A.; Santamaria-Perez, D.; Popescu, C.; Gomis, O.; Manjon, F. J.; Vilaplana Cerda, R.I.; Muñoz, A.; Rodriguez-Hernandez, P.; Ursaki, V. V.; Tiginyanu, I. M. (2014). Structural and vibrational properties of CdAl2S4 under high pressure: Experimental and theoretical approach. Journal of Physical Chemistry C. 118:15363-15374. doi:10.1021/jp5037926.

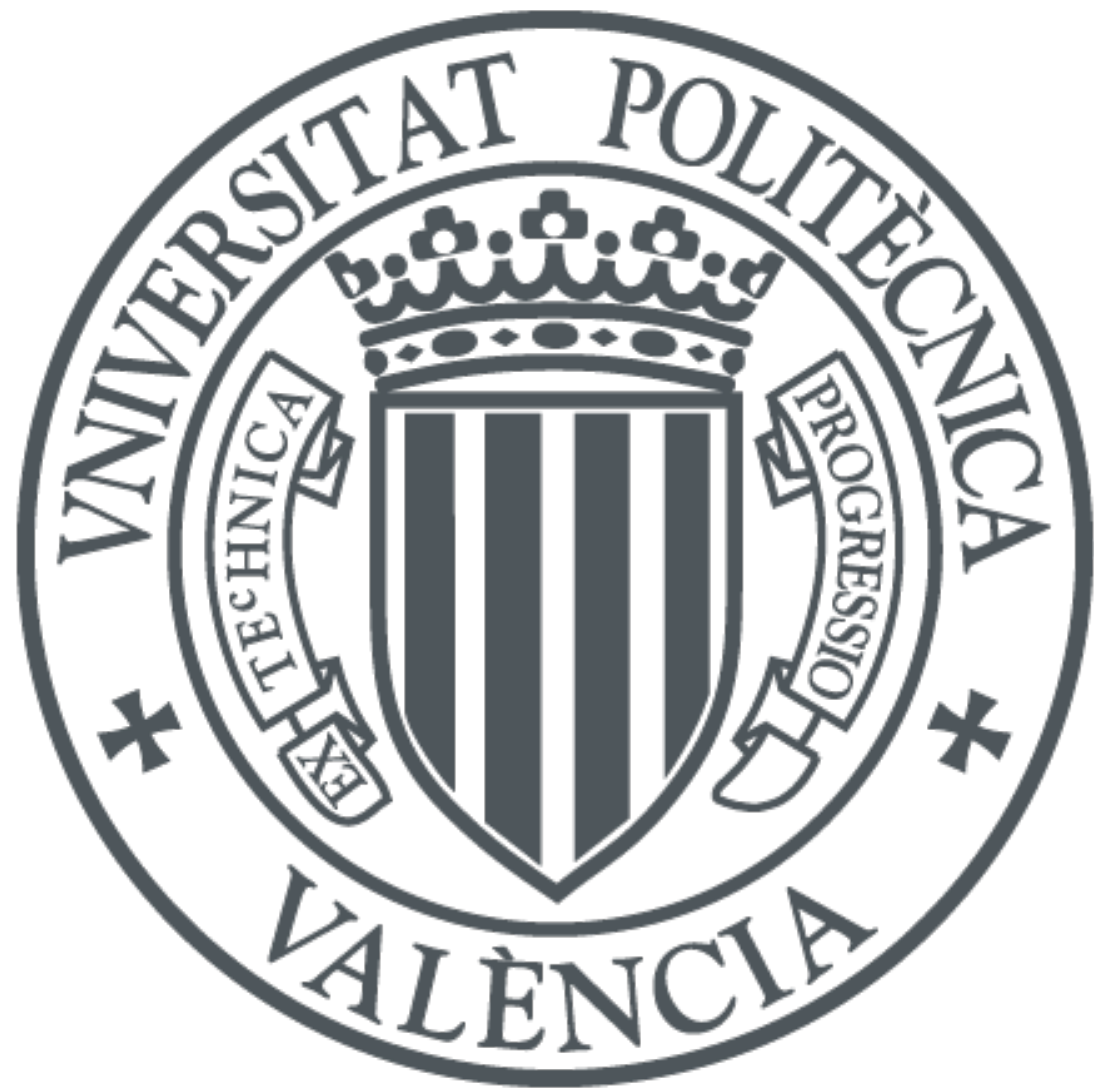

The final publication is available at

http://dx.doi.org/10.1021/jp5037926

Copyright American Chemical Society

Additional Information

"This document is the Accepted Manuscript version of a Published Work that appeared in final form in

Journal of Physical Chemistry C, copyright (C) American Chemical Society after peer review and technical editing by the publisher.

To access the final edited and published work see http://dx.doi.org/10.1021/jp5037926." 


\section{Structural and Vibrational Properties of $\mathrm{CdAl}_{2} \mathrm{~S}_{4}$}

\section{under High Pressure: Experimental and Theoretical}

\section{Approach}

Juan Ángel Sans, ${ }^{*, T}$ David Santamaría-Pérez, ${ }^{1, £}$ Catalin Popescu, ${ }^{\dagger}$ Oscar Gomis, ${ }^{*}$ Francisco Javier Manjón, ${ }^{\mp}$ Rosario Vilaplana ${ }^{\star}$, Alfonso Muñoz, ${ }^{\zeta}$ Plácida Rodríguez-Hernández, ${ }^{\zeta}$ Veaceslav V. Ursaki, ${ }^{\xi}$ and Ion M. Tiginyanu ${ }^{\xi}$

${ }^{\mathrm{T}}$ Instituto de Diseño para la Fabricación y Producción Automatizada, MALTA Consolider Team, Universitat Politècnica de València, Camí de Vera s/n, 46022 València (Spain).

'Dpto. de Física Aplicada-ICMUV, Universitat de València, Edificio de Investigación, C/. Dr. Moliner 50, 46100 Burjassot, Valencia, (Spain)

${ }^{£}$ Earth Sciences Department, University College London, Gower Street WC1E 6BT, London (UK)

${ }^{\dagger}$ CELLS- ALBA Synchrotron Light Source, 08290 Cerdanyola del Valles, Barcelona (Spain)

${ }^{\ddagger}$ Centro de Tecnologías Físicas: Acústica, Materiales y Astrofísica, MALTA Consolider Team, Universitat Politècnica de València, 46022 València, Spain 
${ }^{\zeta}$ MALTA Consolider Team - Departamento de Física, Instituto Univ. de Materiales y Nanotecnología, Universidad de La Laguna, La Laguna, Tenerife (Spain)

${ }^{\xi}$ Institute of Electronic Engineering and Nanotechnologies, Academy of Sciences of Moldova, 2028 Chisinau (Moldova)

ABSTRACT The behavior of defect chalcopyrite $\mathrm{CdAl}_{2} \mathrm{~S}_{4}$ at high pressures and ambient temperature has been studied from a joint experimental and theoretical point of view. Highpressure x-ray diffraction and Raman scattering measurements have been complemented with theoretical ab initio calculations. The equation of state and pressure dependences of the structural parameters of $\mathrm{CdAl}_{2} \mathrm{~S}_{4}$ have been determined and compared to those of other $A B_{2} X_{4}$ orderedvacancy compounds. The pressure dependence of the Raman-active mode frequencies has been reported as well as the theoretical phonon dispersion curves and phonon density of states at 1 atm. Our measurements suggest that defect chalcopyrite $\mathrm{CdAl}_{2} \mathrm{~S}_{4}$ undergoes a phase transition above $15 \mathrm{GPa}$ to a disordered-rocksalt structure, whose equation of state has also been obtained up to $25 \mathrm{GPa}$. In downstroke from $25 \mathrm{GPa}$ to $1 \mathrm{~atm}$, our measurements evidence that $\mathrm{CdAl}_{2} \mathrm{~S}_{4}$ does not return to the defect chalcopyrite phase; it partially retains the disordered-rocksalt phase and partially transforms to the spinel structure. The nature of the spinel structure is confirmed by the good agreement of our experimental results with our theoretical calculations. All in all, our experimental and theoretical results provide evidence that the spinel and defect chalcopyrite phases of $\mathrm{CdAl}_{2} \mathrm{~S}_{4}$ are competitive at $1 \mathrm{~atm}$. This result opens the way to the synthesis of spineltype $\mathrm{CdAl}_{2} \mathrm{~S}_{4}$ near ambient conditions.

KEYWORDS defect chalcopyrite, spinel, ordered vacancy compounds, high-pressure, x-ray diffraction, Raman 


\section{INTRODUCTION}

There is a vast number of compounds with $A B_{2} X_{4}$ stoichiometry, where $A$ and $B$ refer to cations and $X$ corresponds to the anion, depending on the cation and anion valences to fit the octet rule. All the families of $A B_{2} X_{4}$ compounds have one thing in common; i.e, they have an unbalanced number of cations (3) and anions (4) per formula unit. Therefore, from the point of view of structural phase transitions at different temperatures or pressures, these compounds are prone to suffer order-disorder processes where cations may get mixed with vacancies at cation sites to fulfill the requirements of highly-coordinated structures.

Chalcogenides with $A^{I I} B_{2}{ }^{I I I} X_{4}{ }^{V I}$ stoichiometry constitute a vast family of compounds crystallizing at ambient conditions in a great variety of structures. However, they can be classified into three main groups: i) compounds crystallizing in the spinel or related structures; ii) compounds crystallizing in tetrahedrally-coordinated structures, derived from the diamond and zincblende structures with ordered vacancies in the unit cell and known as adamantine-type ordered-vacancy compounds (OVCs); and iii) compounds crystallizing in structures not related to those of spinel or to those of OVCs, e.g. layered materials. Usually, oxides belong to the first group, selenides and tellurides to the second group, and sulphides belong either to the first, to the second, or to the third group.

Adamantine OVCs crystallize in tetragonal structures resulting from the doubling of the cubic zincblende unit cell along the c axis. These tetragonal structures, mainly with defect chalcopyrite (DC) structure [space group (S.G.) I-4, No. 82, Z=2, Fig. 1(a)] or defect stannite (DS) structure [S.G. I-42m, No.121, Z=2], confers to the OVCs special properties not present in cubic zincblende-type compounds. Consequently, adamantine OVC have important applications in optoelectronics, solar cells, and non-linear optics that have attracted considerable attention in the 
last thirty years. ${ }^{1-4}$ In particular, $\mathrm{CdAl}_{2} \mathrm{~S}_{4}$ is a promising thioalluminate semiconductor applicable to photonic devices in the blue spectral region because of their wide band gap with a direct band structure. $^{5,6}$

In the last decade, there has been an increasing interest in understanding the high pressure (HP) behavior of OVCs at ambient temperature as recently reviewed. ${ }^{7,8,9}$ Most of the HP studies of OVCs have been devoted to selenides and only a few to tellurides ${ }^{10}$ and sulfides. ${ }^{11-18}$ In particular, DC-CdAl $\mathrm{S}_{4}$ has been the subject of several HP x-ray diffraction (XRD) and Raman scattering (RS) studies. ${ }^{11,13,15}$ These works have shown contradictory results regarding the structure of the recovered sample after pressure loading. On the other hand, a recent study has predicted that $\mathrm{CdAl}_{2} \mathrm{~S}_{4}$ is a compound which is in the borderline between spinel-type and defect chalcopyrite-type $A B_{2} X_{4}$ compounds. ${ }^{19}$ It is noteworthy to highlight that $\mathrm{CdAl}_{2} \mathrm{~S}_{4}$ shows the highest tetragonal distortion of all compounds crystallizing in the DC structure. Therefore, the HP study of $\mathrm{CdAl}_{2} \mathrm{~S}_{4}$ could provide interesting information about the stability frontiers between different structures of $A B_{2} X_{4}$ compounds.

The above considerations have made us turn our attention to $\mathrm{CdAl}_{2} \mathrm{~S}_{4}$. In the present work, a combined experimental and theoretical investigation of the structural and vibrational behavior of $\mathrm{CdAl}_{2} \mathrm{~S}_{4}$ under pressure during two HP cycles is reported. Angle-dispersive XRD and RS measurements have been compared to theoretical ab initio calculations. The experimental and theoretical equation of state (EOS) for the DC phase and the pressure dependence of the Ramanactive modes for the DC phase are reported and discussed in relation to other OVCs. Furthermore, it is shown that $\mathrm{CdAl}_{2} \mathrm{~S}_{4}$ can be recovered at ambient conditions in the spinel phase in downstroke from $25 \mathrm{GPa}$. This result is in good agreement with our theoretical calculations 
that confirm that $\mathrm{CdAl}_{2} \mathrm{~S}_{4}$ is on the borderline between spinel-type and DC-type $A B_{2} X_{4}$ compounds and that both phases are indeed competitive at $1 \mathrm{~atm}$.

\section{EXPERIMENTAL METHODS}

Schwer and Krämer determined that $\mathrm{CdAl}_{2} \mathrm{~S}_{4}$ crystallizes in the ordered DC structure at ambient conditions. ${ }^{20}$ Samples used in the present study were single crystals of DC-CdAl $\mathrm{S}_{4}$ grown from CdS and $\mathrm{Al}_{2} \mathrm{~S}_{3}$ precursors by chemical vapor transport method using iodine as a transport agent. ${ }^{21}$ Chemical and structural analyses showed the stoichiometric composition of the crystals and that no spurious phases are present. For HP experiments, samples were loaded in the $150 \mu \mathrm{m}$ diameter hole of an Inconel gasket inside a membrane-type diamond anvil cell with a 16:3:1 methanol-ethanol-water mixture as a pressure-transmitting medium, which behaves hydrostatically up to $10.5 \mathrm{GPa}$ and quasi-hydrostatically up to the maximum pressure attained in this study $(25 \mathrm{GPa}) .{ }^{22,23}$ In a HP experiment the error sources in the pressure calibration are coming not only from the loss of hydrostaticity but from the difference in the radial distribution of pressure inside the pressure cavity, the stress produced in the pressure gauge by the sample itself, etc. These different error sources make that the error produced in the determination of the pressure by the loss of hydrostaticity of the pressure-transmitting medium is not relevant below $15 \mathrm{GPa}$ for 16:3:1 methanol-ethanol-water mixture, as it was already observed in Ref 23.

HP-XRD experiments were conducted at $300 \mathrm{~K}$ up to $25.5 \mathrm{GPa}$ on powder (obtained by milling single crystals) and a single crystal of $\mathrm{CdAl}_{2} \mathrm{~S}_{4}$ at the MSPD-BL04 beamline ${ }^{24}$ of the ALBA Synchrotron Light Source using monochromatic $0.4246 \AA$ wavelength. Pressure was estimated with the ruby fluorescence method ${ }^{25,26}$ and simultaneously with the EOS of copper, ${ }^{27}$ which was added as an additional pressure gauge. The observed intensities were integrated as a function of 
$2 \theta$ in order to give one-dimensional diffraction profiles. The indexing and refinement of the powder diffraction patterns were performed using the FULLPROF ${ }^{28}$ and GSAS $^{29}$ program packages.

Unpolarized HP-RS measurements were performed at ambient temperature with a HORIBAJobin Yvon LabRAM HR UV microspectrometer coupled to a Peltier-cooled charged-coupled device camera and using a $632.81 \mathrm{~nm}(1.96 \mathrm{eV}) \mathrm{HeNe}$ laser excitation line with a power smaller than $10 \mathrm{~mW}$ and a spectral resolution better than $2 \mathrm{~cm}^{-1}$. During RS experiments, single-crystal samples were checked by optical inspection before and after each measurement and by means of RS measurements in two different points of the sample with different powers $(10 \mathrm{~mW}$ and 1 $\mathrm{mW}$ ) in order to be sure that no radiation damage nor thermal heating effect occurs during the measurements by the incoming laser excitation. In order to analyze the Raman spectra under pressure, narrow Raman peaks have been fitted, when possible, to a Voigt profile (Lorentzian profile convoluted by a Gaussian profile) where the resolution of the micro-optical system is taken as a fixed Gaussian width. Broad Raman peaks have been directly fitted to Gaussians, where the real Gaussian was obtained after deconvoluting the Gaussian width given by the resolution of the micro-optical system.

\section{THEORETICAL CALCULATIONS}

Total-energy ab initio calculations were carried out for $\mathrm{CdAl}_{2} \mathrm{~S}_{4}$ considering several possible structures, namely: DC-structure; spinel-type (S.G. Fd-3m, No. 227); S.G. Imma, No. 74; $\mathrm{CaFe}_{2} \mathrm{O}_{4}$-type (S.G. Pnma, No. 62); $\mathrm{CaTi}_{2} \mathrm{O}_{4}$-type (S.G. Cmcm, No. 63); and $\mathrm{CaMn}_{2} \mathrm{O}_{4}$-type (S.G. Pbcm, No. 57). Ab initio simulations were performed within the framework of the density functional theory (DFT) and the pseudopotential method as implemented in the Vienna ab initio 
simulation package (VASP) of which a detailed account can be found in Ref. 30 and references therein. The exchange and correlation energy was taken in the generalized gradient approximation (GGA) according to the Perdew-Burke-Ernzerhof prescription for solids (PBEsol). ${ }^{31}$ The projector augmented wave scheme ${ }^{32}$ was adopted to take into account the full nodal character of the all-electron charge density distribution in the core region. The semicore $4 \mathrm{~d}$ electrons of Cd were dealt with explicitly. The basis sets employed included planes waves up to a kinetic energy cutoff of $370 \mathrm{eV}$ to achieve highly converged results that ensure an accurate description of the electronic properties.

The Monkhorst-Pack scheme was used for the Brillouin zone integrations in each of the above mentioned structures. We used a dense mesh of k-points to obtain a high precision in the calculation of energies (about $1 \mathrm{meV}$ per formula unit) and the forces on the atoms. At each selected volume, the structures here considered were fully relaxed to their equilibrium configuration through the calculation of the forces and the stress tensor until the forces on the atoms were smaller than $0.004 \mathrm{eV} / \AA$ and the deviation of the stress tensor from a diagonal hydrostatic form was less than 1 kbar. Details of our total-energy calculations can be already found in literature for the DC-structure, ${ }^{33-35}$ spinel-type and Imma structures,${ }^{36}$ as well as for the $\mathrm{CaFe}_{2} \mathrm{O}_{4}, \mathrm{CaTi}_{2} \mathrm{O}_{4}$ and $\mathrm{CaMn}_{2} \mathrm{O}_{4}$-type structures. ${ }^{37}$

The application of DFT-based total-energy calculations to the study of semiconductors is a well-established method that describes correctly the phase stability and the electronic and dynamical properties of compounds under HP. ${ }^{38}$

Lattice-dynamics calculations of phonon modes were performed in the DC and spinel structures at the zone center ( $\Gamma$ point) of the Brillouin zone. For the calculation of the dynamical matrix at the $\Gamma$ point, we used the direct force-constant approach ${ }^{37}$ which requires highly 
converged results on forces. The construction of the dynamical matrix involves separate calculations of the forces considering fixed displacements from the equilibrium configuration of the atoms within the primitive unit cell. The number of needed independent displacements in the analyzed structures is reduced due to the crystal symmetry. Diagonalization of the dynamical matrix provides the frequencies of the normal modes. Moreover, these calculations allow identifying the symmetry and eigenvectors of the vibrational modes in each structure at the $\Gamma$ point. Details of our lattice dynamics calculations for the DC structure can be consulted in Ref. 34 and those of the spinel structure in Ref. 37.

In order to include the transversal-longitudinal optic (TO-LO) splitting of polar B and E modes at the $\Gamma$ point in the DC phase at different pressures, we performed lattice-dynamics calculations in the framework of Density Functional Perturbation Theory (DFPT) ${ }^{39}$ with the Quantum Espresso package. ${ }^{40}$ In this package, the electric field, that it is not included in the previous direct force method was considered by adding the non-analytic term due to the long-range interaction. For these calculations, we have used ultra-soft pseudopotentials with a cutoff of $60 \mathrm{Ry}$, a big sampling of k-special points to obtain well converged results, and the same exchange correlation prescription used in the total-energy and lattice-dynamics DFT calculations. We have checked that for a given pressure this method yields similar phonon frequencies than DFT calculation with the direct method. ${ }^{41}$

\section{RESULTS AND DISCUSSION}

\section{XRD measurements in DC-CdAl $\mathrm{S}_{4}$}

Ambient temperature angle-dispersive XRD patterns of DC-CdAl $\mathrm{S}_{4}$ at selected pressures up to $25.5 \mathrm{GPa}$ are displayed in Fig. 2. Diffraction patterns can be indexed with the DC structure up 
to $11.3 \mathrm{GPa}$. Above this pressure, two extra peaks appear in the XRD patterns (see marks in the spectrum at $13 \mathrm{GPa}$ ). They can be assigned to the (200) and (220) Bragg reflections of a disordered rocksalt (DR) phase [S.G. Fm-3m, No.225, Z=1], as it was observed in Ref. 13. It is noteworthy that the DC-to-DR phase transition has been observed in many $A B_{2} X_{4}$ OVCs at $\mathrm{HP}$ and $300 \mathrm{~K}$. For $\mathrm{CdAl}_{2} \mathrm{~S}_{4}$, this transition entails a volume collapse of $8.7 \%$, which is similar to that found in a previous HP-XRD study $(7 \%),{ }^{15}$ and similar to that found in other OVCs. The transition pressure in our XRD study $(\sim 12 \mathrm{GPa})$ is larger than that found in a previous HP-XRD study $(9 \mathrm{GPa}),{ }^{15}$ but it is in very good agreement with the previous HP-RS studies (14 GPa). ${ }^{11,13}$ An example of the most relevant Rietveld refinements carried out in this work is shown in Fig. 3. At low pressure $(0.5 \mathrm{GPa})$, our XRD pattern can be refined to a DC-structure with a good Rfactor $\left(\mathrm{R}_{\mathrm{wp}}=2.3 \%\right)$, as shown by comparison with the calculated XRD profile plotted in the figure. At the highest pressure reached $(25.5 \mathrm{GPa})$, the experimental XRD pattern can be assigned to the DR structure $\left(\mathrm{R}_{\mathrm{wp}}=3.4 \%\right)$.

When pressure was released to $1 \mathrm{~atm}, \mathrm{XRD}$ patterns revealed the presence of a new phase (see Bragg peaks at $7-8^{\circ}$ of the released powder sample in Fib. 3) in coexistence with the DR phase. In order to favor the transition after release of pressure, we tried to heat the sample with a 488 $\mathrm{nm}$ laser operating at $40 \mathrm{~mW}$ for a reduced time (3 hours). Unfortunately, the XRD patterns taken afterwards did not show evident changes. Note that the XRD pattern of the releasedpowder sample in Fig. 3 continues showing a good Rietveld refinement with the DR phase $\left(\mathrm{R}_{\mathrm{wp}}=4.6 \%\right)$ even though the presence of the new phase is not taken into account. In order to improve this refinement and identify the new phase, we tentatively performed a Le Bail refinement of this diffraction pattern to a spinel phase. Figure 3 shows indeed an improvement of the correlation factor $\left(\mathrm{R}_{\mathrm{wp}}=4.0 \%\right)$ and a relatively good approach to the identification of this new 
phase, obtaining a lattice parameter of $a=10.33(2) \AA$ for the spinel structure, when both DR and spinel phases are considered together.

We must notice that the amount of DR-CdAl ${ }_{2} \mathrm{~S}_{4}$ undergoing a transition to the spinel structure at $1 \mathrm{~atm}$ is very small. This result could explain why previous RS experiments showed that most of the sample remains in the metastable DR phase at ambient conditions. ${ }^{11}$ In fact, the observation of the spinel phase on decreasing pressure in $\mathrm{CdAl}_{2} \mathrm{~S}_{4}$ at $300 \mathrm{~K}$ and $1 \mathrm{~atm}$ could appear rather surprising at first glance. In the last decade it has been shown that many OVCs either retain the DR phase metastable at $1 \mathrm{~atm}$ or they undergo a phase transition from the DR phase to the disordered zincblende (DZ) structure (S.G. F-43m, No. 216, Z=1) at $1 \mathrm{~atm}$. We will discuss in more detail the transformation of $\mathrm{DC}-\mathrm{CdAl}_{2} \mathrm{~S}_{4}$ to the spinel structure in the next section after considering RS measurements and theoretical calculations which will allow us to get a deeper insight into this problem. It is important, however, to point out that Meenakshi et al. ${ }^{15}$ reported an additional phase upon unloading which they attributed to the DZ structure, which has not been observed in our experimental study. Curiously, the most intense Bragg peak of the DZ-CdAl $\mathrm{S}_{4}$ in Ref. 15 should appear around $12^{\circ}$ corresponding to the (111) Bragg peak but this feature is not observed in the XRD patterns provided in that work in figure 2 . Noteworthy, this peak is indeed reported by Meenakshi et al. in figure 1 of the same work for DC- $-\mathrm{HgAl}_{2} \mathrm{Se}_{4}$ on decreasing pressure. The most clear Bragg peak used by Meenakshi et al. to identify the $\mathrm{DZ}$ phase in $\mathrm{CdAl}_{2} \mathrm{~S}_{4}$ was the peak observed around $19^{\circ}$ assigned to the $(220)$ peak of the DZ phase; however, we must note that this feature could also be assigned to the (220) peak of the DR phase. Moreover, the (331) peak of the DZ phase is close to the (420) Bragg peak of the DR phase. Therefore, taking into account all these considerations we think that the XRD pattern shown in Ref. 15 for the released sample of $\mathrm{CdAl}_{2} \mathrm{~S}_{4}$ is not consistent with the $\mathrm{DZ}$ phase 
but it is consistent with the metastable DR phase already observed in the previous work of Burlakov et al. ${ }^{11}$

From the refinements of XRD patterns collected under compression, the evolution of the unitcell parameters and atomic positions of the DC structure can be obtained as a function of pressure. Figure 4(a) shows the pressure dependence of the volume for $\mathrm{DC}-\mathrm{CdAl}_{2} \mathrm{~S}_{4}$. A fit to the DC-CdAl $\mathrm{S}_{4}$ volume data with a third-order Birch-Murnaghan EOS yields a zero-pressure volume $\mathrm{V}_{0}=310.6(4) \AA^{3}$, a bulk modulus $\mathrm{B}_{0}=41.2(16) \mathrm{GPa}$, and a first bulk modulus derivative with pressure $\mathrm{B}^{\prime}{ }_{0}=5.4(4)$. Our value for the $\mathrm{B}_{0}$ and $\mathrm{B}^{\prime}{ }_{0}$ compare nicely with those obtained in our first-principles calculations $\left(\mathrm{B}_{0}=40 \mathrm{GPa}\right.$ with $\left.\mathrm{B}_{0}{ }_{0}=4.9\right)$, being our $\mathrm{B}_{0}$ similar to the one reported previously by Meenakshi et al. despite having different $\mathrm{B}_{0}{ }_{0}\left(\mathrm{~B}_{0}=44.6 \mathrm{GPa}\right.$ with $\mathrm{B}_{0}{ }_{0}=$ $4.0) .^{15}$

The atomic coordinates of $\mathrm{S}$ atoms (Wyckoff position $8 \mathrm{~g},(\mathrm{x}, \mathrm{y}, \mathrm{z})$ ) in $\mathrm{DC}-\mathrm{CdAl}_{2} \mathrm{~S}_{4}$ at 1 atm were estimated from Rietveld refinement of XRD in a capillary tube. The obtained values are similar to those reported by Schwer and $\mathrm{Krämer}^{20}$ and agree with our theoretical values (see Table 1). Trials to get the pressure dependence of the atomic coordinates of $\mathrm{S}$ atoms in the whole pressure range of stability of the DC phase, were not fruitful due to the non-uniform crystal sizes of our powder sample.

As regards the pressure dependence of the $a$ and $c$ lattice parameters in DC-CdAl $\mathrm{S}_{4}$, Fig. 4(b) shows that they decrease as a function of pressure from $a=5.541 \AA$ and $c=10.085 \AA$ at 1 atm to $a=5.252 \AA$ and $c=9.664 \AA$ at $9.9 \mathrm{GPa}$. Fits with a Birch-Murnaghan EOS yield compresibilities for $a$ and $c$ axes at $1 \mathrm{~atm}$ of $\kappa_{a}=6.12 \cdot 10^{-3} \mathrm{GPa}^{-1}$ and $\kappa_{c}=8.90 \cdot 10^{-3} \mathrm{GPa}^{-1}$, which are similar to our theoretical ones $\left(\kappa_{a}=6.26 \cdot 10^{-3} \mathrm{GPa}^{-1}\right.$ and $\left.\kappa_{c}=1.26 \cdot 10^{-2} \mathrm{GPa}^{-1}\right)$ and are similar to those reported previously for $\mathrm{CdAl}_{2} \mathrm{~S}_{4}{ }^{15}$ and other OVCs. ${ }^{14,34,42-44}$ 
Now, we are going to discuss the effect of pressure on bond distances and polyhedral of DC$\mathrm{CdAl}_{2} \mathrm{~S}_{4}$. The DC structure is formed by four different tetrahedra (one around each of the three different cation positions and one around the cation vacancy), where the central position is surrounded by $\mathrm{S}$ anions. Note that $\mathrm{Al}$ cations are in 2a and 2c Wyckoff sites whereas the vacancy and the $\mathrm{Cd}$ cation are located at $2 \mathrm{~b}$ and $2 \mathrm{c}$ Wyckoff sites respectively (see Fig. 1). The tetrahedron around $\mathrm{Al}$ at $2 \mathrm{a}(2 \mathrm{c})$ sites has an average $\mathrm{Al}-\mathrm{S}$ bond length $\mathrm{d}_{\mathrm{Al}-\mathrm{S}}=2.27 \AA(2.33 \AA)$ and a volume of $\mathrm{V}_{\mathrm{Al}-\mathrm{S}}=5.99 \AA^{3}\left(6.37 \AA^{3}\right)$, which compare with those of the regular tetrahedron in the binary $\mathrm{Al}_{2} \mathrm{~S}_{3}$ compound $\left(\mathrm{d}_{\mathrm{Al}-\mathrm{S}}=2.29 \AA\right.$ and $\left.\mathrm{V}_{\mathrm{Al}-\mathrm{S}}=6.16 \AA^{3}\right)$. These results indicate that both tetrahedra around $\mathrm{Al}$ atoms in $\mathrm{DC}-\mathrm{CdAl}_{2} \mathrm{~S}_{4}$ are distorted (in fact they are expanded compared to the tetrahedron in the binary compound) and they are distorted in a different fashion. The distortion of a polyhedron unit can be estimated by deviation of the quadratic elongation $\langle\lambda\rangle$ from 1,45

$$
\langle\lambda\rangle=\frac{1}{n} \sum_{i=1}^{n}\left(\frac{l_{i}}{l_{0}}\right)^{2}
$$

where $l_{i}$ is each of the $n$ cation-anion distances that forms the real polyhedron and $l_{0}$ is the theoretical bond-length in the case of a regular polyhedron. The quadratic elongation of the tetrahedron around $\mathrm{Al}$ at $2 \mathrm{a}(2 \mathrm{c})$ is 1.009 (1.017), which compares to the value of 1 in the regular tetrahedron formed in $\mathrm{Al}_{2} \mathrm{~S}_{3}$. These results clearly indicate that the tetrahedron formed by $\mathrm{S}$ anions around $\mathrm{Al}(2 \mathrm{a})$ cations, which are in the same plane of the vacancies perpendicular to the $c$ axis is less distorted than the one around $\mathrm{Al}(2 \mathrm{c})$ cations. On the other hand, the tetrahedron centered in the $\mathrm{Cd}(2 \mathrm{~d})$ cation has an average Cd-S bond length of $\mathrm{d}_{\mathrm{Cd}-\mathrm{S}}=2.49 \AA$ and a volume of $\mathrm{V}_{\mathrm{Cd}-\mathrm{S}}=7.88 \AA^{3}$ which can be compared to those in the wurtzite-type binary compound CdS $\left(\mathrm{d}_{\mathrm{Cd}-}\right.$ $\mathrm{S}=2.53 \AA$ and $\left.\mathrm{V}_{\mathrm{Cd}-\mathrm{S}}=8.29 \AA^{3}\right) .{ }^{46}$ It can be concluded that the tetrahedron centered in Cd cation in DC-CdAl $\mathrm{S}_{4}$ is compressed in comparison with $\mathrm{CdS}$. This result is a clear signature of the key 
role played by the chemical pressure and it is consistent with the higher sensitivity of the $\mathrm{Cd}$ tetrahedron than the $\mathrm{Al}$ tetrahedron to external pressure as it is demonstrated by our theoretical interatomic bond length compressibilities. In other words, the Cd-S bonds are considerably more compressible than the Al-S bonds, as expected by the larger volume of the tetrahedron around $\mathrm{Cd}$ atom than around $\mathrm{Al}$ atoms

Furthermore, we have compared the quadratic elongation suffered by the tetrahedron formed by $\mathrm{Cd}-X$ (being $X$ the anion) in DC-CdAl${ }_{2} \mathrm{~S}_{4}$ with other OVCs crystallizing in the DC structure at ambient conditions, like DC-CdAl $\mathrm{Se}_{4}$ and DC-CdGa $\mathrm{S}_{4}$. These two materials show the same HP phase when we apply pressure at ambient temperature (DR structure) remaining this HP structure metastable after the decompression. ${ }^{14,47}$ These compounds have a quadratic elongation in the tetrahedra formed by the $\mathrm{Cd}-X$ of 1.0001 (1.0012) for $\mathrm{CdGa}_{2} \mathrm{~S}_{4}\left(\mathrm{CdAl}_{2} \mathrm{Se}_{4}\right)$ which are smaller than the value for $\mathrm{DC}-\mathrm{CdAl}_{2} \mathrm{~S}_{4}$ (1.017). The higher quadratic elongation observed for DC$\mathrm{CdAl}_{2} \mathrm{~S}_{4}$ could indicate that the DC structure is not as stable in $\mathrm{CdAl}_{2} \mathrm{~S}_{4}$ as in the other two compounds. This argument seems to be in good agreement with the observation of Zhang and Zunger ${ }^{19}$ who have considered $\mathrm{CdAl}_{2} \mathrm{~S}_{4}$ in the borderline between spinel-type and defect chalcopyrite-type $A B_{2} X_{4}$ compounds.

We also want to comment on the pressure dependence of the cla ratio of the DC phase since the tetragonal distortion, $\delta=2-c / a$, could give important information about the behavior of the sample under compression. In this respect, it is important to note that DC-CdAl $2 \mathrm{~S}_{4}$, together with DC-CdGa $\mathrm{S}_{4}$, exhibits the highest tetragonal distortion reported in OVCs $(\delta=0.165)$ at $1 \mathrm{~atm}$. Figure 4(b) shows the pressure dependence of the $c / a$ ratio vs. pressure for $\mathrm{DC}-\mathrm{CdAl}_{2} \mathrm{~S}_{4}$. The $c / a$ ratio increases smoothly from 1.82 at 1 atm to 1.84 at $9.9 \mathrm{GPa}$. However, at $11.3 \mathrm{GPa}$ where the onset of the phase transition to the DR phase occurs, the unit cell parameters change drastically; 
i.e. the $c$ axis increases and the $a$ axis collapses, in such a way that the volume decrease continuously with pressure (see Fig. 4(a)) and the $c / a$ ratio jumps to almost 1.88 . This result contrasts with our first-principles calculations, where this ratio increases continuously with pressure from 1.83 to 1.88 (see Fig. 4(b)).

Finally, as regards the HP phase with sixfold coordinated DR structure, a third-order BirchMurnaghan EOS (see Fig. 4(a)) yields: $\mathrm{V}_{0}=138.5(3) \AA^{3}, \mathrm{~B}_{0}=54(4) \mathrm{GPa}$ and $\mathrm{B}_{0}$ '= 5.5(9), being the zero-pressure lattice parameter $a=5.1740(16) \AA$. These results are in overall good agreement with those previously reported by Meenakshi et al. ${ }^{15}$ and confirm that the DR phase is less compressible than the DC phase. The structural parameters obtained for $\mathrm{DR}-\mathrm{CdAl}_{2} \mathrm{~S}_{4}$ are equivalent to similar DR phases in other OVCs, like as $\mathrm{HgGa}_{2} \mathrm{Se}_{4}$ with a zero-pressure lattice parameter of 5.2048(5) $\AA .^{44}$

\section{RS measurements in $\mathrm{DC}-\mathrm{CdAl}_{2} \mathrm{~S}_{4}$}

According to group theory, ${ }^{48}$ the DC-structure of $\mathrm{CdAl}_{2} \mathrm{~S}_{4}$ has twenty-one vibrational modes at $\Gamma$ with mechanical representation:

$$
\Gamma=3 \mathrm{~A}(\mathrm{R}) \oplus 5 \mathrm{~B}(\mathrm{R}, \mathrm{IR}) \oplus 5 \mathrm{E}(\mathrm{R}, \mathrm{IR}) \oplus \mathrm{B} \oplus \mathrm{E}
$$

where B and E (A) are polar (non-polar) modes and E modes are doubly degenerated. This results in a total of eighteen Raman-active $(R)$ modes $(3 A \oplus 5 B \oplus 5 \mathrm{E})$, fifteen IR modes $(5 \mathrm{~B} \oplus$ 5E) and three acoustic modes $(\mathrm{B} \oplus \mathrm{E})$. It is interesting to note that doubly degenerate $\mathrm{E}$ modes correspond to vibrations of atoms along the $a$ and $b$ axis; i.e., in the directions perpendicular to the $c$ axis, while $\mathrm{B}$ modes correspond to vibrations of atoms along the $c$ axis. In addition, two 
peaks (either R or IR) should be observed for each B and E modes in the DC structure due to the LO-TO splitting of the polar modes. Consequently, taking into account the LO-TO splitting, up to twenty-three Raman-active modes and twenty IR-active modes could be observed in DC$\mathrm{CdAl}_{2} \mathrm{~S}_{4}$

Figure 5 shows the theoretical phonon dispersion curves in $\mathrm{DC}-\mathrm{CdAl}_{2} \mathrm{~S}_{4}$ along different symmetry points of the Brillouin zone and the corresponding total and atom-projected phonon density of states. This figure allows one to divide the vibrational spectrum, like in other $A B_{2} X_{4}$ OVCs, mainly into three regions: (i) the low-frequency region below $200 \mathrm{~cm}^{-1}$, (ii) the mediumfrequency region between 200 and $360 \mathrm{~cm}^{-1}$, and (iii) the high-frequency region above $360 \mathrm{~cm}^{-1}$. In the low-frequency region, the phonon density of states displayed shows that $\mathrm{Cd}$ atoms dominate the vibrations below $80 \mathrm{~cm}^{-1}$ while $\mathrm{S}$ atoms dominate above $80 \mathrm{~cm}^{-1}$, with a minor contribution of $\mathrm{Cd}$ and $\mathrm{Al}$ atoms. In the medium-frequency region, the $\mathrm{S}$ contribution is even more dominant than in the low-frequency region. This explains why all modes with A symmetry, which correspond to the vibrations of $\mathrm{S}$ atoms around the vacancy, are located in the medium frequency region while $\mathrm{E}$ and $\mathrm{B}$ modes are spread along the three frequency regions. We must note that the most intense peak of the Raman spectrum of DC-CdAl $2 \mathrm{~S}_{4}$ (the $\mathrm{A}^{1}$ mode near 213 $\mathrm{cm}^{-1}$ in Fig. 6(a)) has also a small contribution of $\mathrm{Cd}$ and $\mathrm{Al}$ cations, which could be explained as a result of the perturbation produced in the lattice due to the high intensity of this resonance. In the high-frequency region, the vibrations involve only $\mathrm{Al}$ and $\mathrm{S}$ atoms, thus suggesting that these vibrations are Al-S bond stretching and bond bending modes of the tetrahedron formed by $\mathrm{S}$ anions and $\mathrm{Al}$ cations. The study of the vibration of atoms was further corroborated with J-ICE software, ${ }^{50}$ which allows one to get images of Raman modes as those shown at the bottom of Fig. 5. 
The atomic contribution to vibrations in the high-frequency region, which involves only vibrations of $\mathrm{Al}$ and $\mathrm{S}$, claims for a comparison with the vibrations in the defective spinel $\mathrm{Al}_{2} \mathrm{~S}_{3}$; however, the Raman spectrum of $\mathrm{Al}_{2} \mathrm{~S}_{3}$ has not been obtained yet due to the high sensitivity of this compound to the ambient moisture. ${ }^{49}$ Therefore, we suggest that the high-frequency modes observed in the high-frequency region of $\mathrm{CdAl}_{2} \mathrm{~S}_{4}$ could be considered as a possible extrapolation to the Raman modes that could be found in $\mathrm{Al}_{2} \mathrm{~S}_{3}$.

HP-RS spectra of DC-CdAl $\mathrm{S}_{4}$ up to $15 \mathrm{GPa}$ are shown in Figure 6(a) where the Raman-mode symmetry assignment has been performed on the basis of our theoretical calculations. At low pressures, the RS spectra are similar to those reported by Burlakov et al., ${ }^{11}$ whose spectra and interpretation are also similar to those reported by Razzetti et al. ${ }^{51}$ and Eifler et al. ${ }^{52}$ The pressure dependence of 16 Raman-active modes and the LO-TO splittings in $\mathrm{DC}-\mathrm{CdAl}_{2} \mathrm{~S}_{4}$ corresponding to $\mathrm{E}^{1}, \mathrm{E}^{3}$ and $\mathrm{E}^{5}$ modes have been measured. In particular, we noted that $\mathrm{B}^{4}$ mode becomes relevant from 3.3 GPa onwards, being distinguishable until the phase transition near $13 \mathrm{GPa}$; however, we could not observe the difference between the $\mathrm{E}^{5}$ and $\mathrm{B}^{5} \mathrm{LO}$ modes whose contributions are merged in the Raman peak located at $500 \mathrm{~cm}^{-1}$.

The pressure dependence of the experimental and theoretical (including the TO-LO splitting) Raman mode frequencies of the $\mathrm{DC}-\mathrm{CdAl}_{2} \mathrm{~S}_{4}$ phase up to $15 \mathrm{GPa}$ is shown in Figure 6(b). It can be observed that the peaks in the medium- and high-frequency regions shift to higher frequencies as pressure increases while most of the peaks of the low-frequency region show a small positive or even negative pressure coefficient as it has been previously observed in other $A B_{2} X_{4}$ OVCs. ${ }^{7,8}$ In general, our experimental Raman mode frequencies and pressure coefficients at zero pressure for $\mathrm{DC}-\mathrm{CdAl}_{2} \mathrm{~S}_{4}$ agree with those reported in previous works ${ }^{11,13}$ and with our theoretical values. Therefore, the application of pressure allows us to identify the symmetry of the experimental 
Raman modes with the help of $a b$ initio calculations. The experimental and theoretical Raman mode symmetries, and their frequencies and pressure coefficients at zero pressure, as obtained from fits to the data using the $\omega=\omega_{0}+\mathrm{aP}+\mathrm{bP}^{2}$ equation, are summarized in Table 2.

Note that we have assigned the modes below $220 \mathrm{~cm}^{-1}$ in the same way as Burlakov et al. ${ }^{11}$ However, the symmetry for modes of higher frequencies show some discrepancy with previous results. It must be mentioned that the discrepancies in the assignment of the symmetry of highfrequency modes in OVCs are very common because of the observation of quasi-modes instead of pure modes in uniaxial crystals. ${ }^{17,33,53-55}$ For $\mathrm{CdAl}_{2} \mathrm{~S}_{4}$, the high quality of our Raman spectra and the similarity of the experimental and theoretical pressure dependence of the modes allows a rather clear assignment of the mode symmetry on the light of our theoretical calculations and previous Raman studies. A comparison with previous studies, in particular, with the results of Burlakov et al. ${ }^{11}$, show that our main difference is that in our case we were able to distinguish experimentally between the $\mathrm{B}^{4}$ and $\mathrm{A}^{3}$ modes but not between $\mathrm{E}^{5}$ and $\mathrm{B}^{5} \mathrm{LO}$ modes.

These two last modes were reported with the same pressure coefficient by Burlakov et al. ${ }^{11}$ while our calculations show that the pressure coefficient of $B^{5}(\mathrm{LO})$ is almost two times higher than the one of $E^{5}(\mathrm{LO})$. In this respect, we have interpreted that the highest-frequency mode measured is a mixture of $E^{5}(\mathrm{LO})$ and $\mathrm{B}^{5}(\mathrm{LO})$ but with larger $\mathrm{B}^{5}(\mathrm{LO})$ character (see Fig. 6(b)). We should emphasize that this assignment agrees with those obtained by Eifler et al. ${ }^{52}$ by IR reflectivity and Raman measurements at ambient conditions.

In order to obtain more information on the pressure-induced order-disorder process in DC$\mathrm{CdAl}_{2} \mathrm{~S}_{4}$ related to the phase transition, we have analyzed the pressure dependences of the Raman mode intensities and linewidths of the DC phase as previously done by Burlakov et al. ${ }^{11}$ Our results agree with those of Burlakov et al. ${ }^{11}$ who observed a progressive decrease of the 
intensity of the $\mathrm{A}^{2}$ mode and a simultaneous increase of the $\mathrm{A}^{3}$ mode on increasing pressure. A similar behavior was recently reported for $\mathrm{DC}-\mathrm{CdGa}_{2} \mathrm{Se}_{4}$ and interpreted as a signature of the DC-to-DS pressure-induced phase transition prior to the transition towards the DR phase. ${ }^{34}$ In that paper it was claimed that there are several possible phases (with DS and disordered CuAulike layered structure) with an intermediate degree of cation or cation-vacancy disorder between that of the completely ordered DC phase and that of the completely disordered DZ and DR phases. Furthermore, the number of different intermediate phases with an intermediate degree of disorder between DC and DZ phases has been recently reviewed. ${ }^{53}$ In particular, in the work on DC-CdGa $2 \mathrm{Se}_{4}$, it was suggested that there are two possible DS polytypes (models 2 and 3) with less Raman peaks than the DC phase and which could explain the Raman results. ${ }^{34}$ The existence of this intermediate DS phase in $\mathrm{CdAl}_{2} \mathrm{~S}_{4}$ could be consistent with the observation of the disappearance of the $\mathrm{A}^{2}$ peak above $6 \mathrm{GPa}$ in $\mathrm{DC}-\mathrm{CdAl}_{2} \mathrm{~S}_{4}$.

\section{RS measurements in the HP phase}

All Raman-active modes of $\mathrm{DC}-\mathrm{CdAl}_{2} \mathrm{~S}_{4}$ phase disappear above $13 \mathrm{GPa}$ and a partially flat spectrum is observed. A similar result was observed in previous RS studies above $14 \mathrm{GPa},{ }^{11,13}$ which is consistent with the phase transition to the Raman-inactive DR phase observed by our XRD measurements near $12 \mathrm{GPa}$. This result is similar to that found in many other OVCs which undergo a phase transition to the DR phase above $20 \mathrm{GPa}$, like $\mathrm{CdGa}_{2} \mathrm{Se}_{4}$ and $\mathrm{HgGa} 2 \mathrm{Se} 4 .{ }^{33,42,44,55}$ We must note that the flat RS spectrum shows indeed some very broad peaks with very small intensity as it can be observed in the RS spectrum of $13.7 \mathrm{GPa}$ (see Fig. 6(a)). These small bands could be attributed to defect-assisted RS as already observed in other compounds having a HP rocksalt phase. ${ }^{56}$ 


\section{RS measurements in the recovered phase}

On decreasing pressure from $25 \mathrm{GPa}$ slowly down to $0.5 \mathrm{GPa}$ and leaving the sample to reach equilibrium we noted that the RS spectrum changed considerably and new peaks appeared (see Fig. 7(a)). The RS spectrum of the new phase is characterized by a few Raman modes: a very intense peak near $300 \mathrm{~cm}^{-1}$, two rather weak peaks near 100 and $200 \mathrm{~cm}^{-1}$ and three broad weak bands. The small number of Raman peaks, the narrow FWHM of some peaks, and their different frequencies with respect to those of the initial DC phase clearly indicate that the sample have not recovered the original DC phase nor showed the broad features characteristic of the DZ phase observed in $\mathrm{HgGa}_{2} \mathrm{~S}_{4}, \mathrm{ZnGa}_{2} \mathrm{Se}_{4}, \mathrm{CdGa}_{2} \mathrm{Se}_{4}$ and $\mathrm{HgGa}_{2} \mathrm{Se}_{4}$ in downstroke. ${ }^{17,34,54,55}$

In order to identify the structure of the recovered sample, we performed HP-RS measurements during a second upstroke (see Fig. 7(a)). The pressure dependence of the Raman-active mode frequencies is plotted in Fig. 7(b).

In order to find candidate structures for the new phase, we first resorted to total energy $a b$ initio calculations to evaluate the enthalpy difference vs. pressure of several structures which could be competitive in $\mathrm{CdAl}_{2} \mathrm{~S}_{4}$ (DC-type, spinel-type, defect-LiTiO ${ }_{2}$-type, $\mathrm{CaFe}_{2} \mathrm{O}_{4}$-type, $\mathrm{CaMn}_{2} \mathrm{O}_{4}$-type and $\mathrm{CaTi}_{2} \mathrm{O}_{4}$-type) on the basis of its presence in related compounds. Figure 8 displays the enthalpy difference vs. pressure for these structures. Note that the defect-LiTiO $2_{2}$ type structure was simulated with the Imma structure as in Ref. 36. Our calculations yielded exactly the same enthalpy difference curve for the $\mathrm{CaMn}_{2} \mathrm{O}_{4}$-type structure and for the $\mathrm{CaTi}_{2} \mathrm{O}_{4}-$ type structure. Therefore, only one line is plotted. Our calculations at $\mathrm{T}=0 \mathrm{~K}$ suggest that the spinel phase is the most competitive one with the DC phase at 1 atm. Our GGA-PBEsol (GGAPBE) calculations show that the energy minimum of the spinel phase is below (above) that of the 
DC structure. Our GGA-PBE calculations suggest a phase transition from the DC to the spinel structure around $1 \mathrm{GPa}$. A similar result was obtained by Marinelli et al. for $\mathrm{CdI}_{2} \mathrm{Se}_{4} \cdot{ }^{57}$ Therefore, our results suggest that $\mathrm{CdAl}_{2} \mathrm{~S}_{4}$ could crystallize at ambient conditions in the spinel phase or could be, at least, metastable at ambient conditions. Our lack of observation of the spinel phase at $\mathrm{HP}$ at $300 \mathrm{~K}$ and its observation after a HP treatment (1 GPa) at high temperature $(700 \mathrm{~K})^{58}$ is a clear evidence that there must be a kinetic barrier impeding the DC-to-spinel transformation at $300 \mathrm{~K}$, which could be the reason why the spinel phase can be only obtained at $300 \mathrm{~K}$ in downstroke from the DR phase.

On the basis of the above results, we performed lattice-dynamics calculations for the perfect normal spinel phase at several pressures up to $11 \mathrm{GPa}$. The pressure dependence of the calculated Raman-active mode frequencies of the spinel phase is plotted in Fig. 7(b) with solid lines. As it can be observed, there is a reasonable agreement with the experimental results, especially for the more intense Raman modes. In this context, we must note that the agreement between experiment and theory cannot be perfect for two reasons: i) our sample is a partially inverse spinel with a mixture of $\mathrm{Cd}$ and $\mathrm{Al}$ cations in both cation sites of the spinel lattice while our calculations are performed for a perfect normal spinel structure; and ii) our sample should exhibit some disorder; i.e., vacancies occupying cation sites and cations occupying interstitial sites. These defects are likely due to the partial irreversibility of the pressure-induced order-disorder transition on going from the perfect DC phase to the cation-disordered rocksalt phase.

The Raman modes observed in the recovered sample of $\mathrm{CdAl}_{2} \mathrm{~S}_{4}$ can also be compared with those of $\mathrm{ZnAl}_{2} \mathrm{~S}_{4}$, which can be synthesized (depending on the growth conditions) in the spinel structure ( $\alpha$-phase).$^{59,60}$ In $\alpha-\mathrm{ZnAl}_{2} \mathrm{~S}_{4}$, Ursaki et al. ${ }^{61}$ could only distinguish three main peaks at $133 \mathrm{~cm}^{-1}, 353 \mathrm{~cm}^{-1}$ and $413 \mathrm{~cm}^{-1}$. The most intense feature of $\mathrm{CdAl}_{2} \mathrm{~S}_{4}\left(286 \mathrm{~cm}^{-1}\right)$ is observed at 
smaller frequencies than that of $\alpha-\mathrm{ZnAl}_{2} \mathrm{~S}_{4}\left(353 \mathrm{~cm}^{-1}\right)$ because $\mathrm{Cd}$ is heavier than $\mathrm{Zn}$. Fitting the linear behavior of this Raman mode, we could obtain a good agreement between both compounds $\left(5.5 \mathrm{~cm}^{-1} / \mathrm{GPa}\right.$ for $\mathrm{CdAl}_{2} \mathrm{~S}_{4}$ and $5.45 \mathrm{~cm}^{-1} / \mathrm{GPa}$ for $\left.\alpha-\mathrm{ZnAl}_{2} \mathrm{~S}_{4}\right)$ which is a clear signature of the validity of this assignment.

In order to find more evidences supporting the assignment of the recovered phase in $\mathrm{CdAl}_{2} \mathrm{~S}_{4}$ to the spinel structure and in order to study if the grain size could affect the rate of transformation to the spinel structure, we loaded a single crystal in a DAC and measured XRD in the recovered sample after a pressure cycle (increasing pressure up to $25 \mathrm{GPa}$ and decreasing down to almost $0 \mathrm{GPa}$ ). Due to the evident technical difficulties faced by measuring XRD in a sample which is neither a powder nor a single crystal (since the single crystal is destroyed during the DC-to-DR phase transition), we could not carry out a Rietveld refinement. Instead, we performed a Le Bail refinement with the cubic spinel structure (shown on top of Fig. 3) using the atomic positions at the spinel phase obtained from theoretical calculations. Our XRD results on the recovered single crystal clearly indicate a much larger proportion of the spinel phase than of the metastable DR phase, unlike it was observed in the recovered powder sample. In summary, our analysis clearly indicates that the new phase in downstroke can be identified as the spinel structure in good agreement with our RS results and the high stability of this phase proposed by our theoretical calculations.

From the Le Bail refinement, we obtained a lattice parameter for the spinel phase of $\mathrm{CdAl}_{2} \mathrm{~S}_{4}$ $(a=10.325(4) \AA)$ slightly different (less than $1 \%)$ from the value theoretically predicted $\left(a_{\text {teo }}=\right.$ $10.24 \AA$ ), which is similar to that obtained by Range et al. ${ }^{58}$ who showed that various OVCs (including $\mathrm{CdAl}_{2} \mathrm{~S}_{4}$ ) can be crystallized in the spinel structure after a high-pressure/high temperature treatment. The disagreement with the theoretical value could be due to the degree of 
inversion and cation-vacancy disorder present in our samples and/or the underestimation of the theoretical lattice parameters.

Note that in our case the spinel structure was obtained after a HP treatment at ambient temperature. Therefore, this work suggests that the growth of the spinel phase of $\mathrm{CdAl}_{2} \mathrm{~S}_{4}$ at near ambient temperature is possible. In this respect, our results are in very good agreement with Zhang and Zunger ${ }^{19}$ who systematized the prediction of structures of $A_{2} B X_{4}$ compounds on the basis of quantum-mechanical orbital radii and showed that $\mathrm{CdAl}_{2} \mathrm{~S}_{4}$ is on the borderline between DC and spinel structures.

Finally, it must be mentioned that RS measurements performed in the spinel phase during the second upstroke, evidenced a phase transition above $10 \mathrm{GPa}$ to a structure whose RS spectrum was flat; i.e., resembling that of the previous DR structure. Besides, the RS spectrum of the spinel phase was again recovered on decreasing pressure (see Fig. 7(a)), thus showing the reversibility of this phase transition. Noteworthy, in $\mathrm{ZnAl}_{2} \mathrm{~S}_{4}$ a phase transition from the wurtzite structure towards the DR structure has been reported; however, the spinel phase of $\mathrm{ZnAl}_{2} \mathrm{~S}_{4}$ was observed to undergo a phase transition to the $\mathrm{CaFe}_{2} \mathrm{O}_{4}$-type phase like it has been observed in different oxospinels. ${ }^{61}$ Note that despite $\mathrm{CaTi}_{2} \mathrm{O}_{4}$ shows a higher stability than the post-spinel $\mathrm{CaFe}_{2} \mathrm{O}_{4}$, no evidence of transition towards the former phase has been observed in sulfur compounds. In fact, $\mathrm{Cd}, \mathrm{Mg}$ and $\mathrm{Mn}$ indium thiospinels have been found to undergo a phase transition towards the defect- $\mathrm{LiTiO}_{2}$ structure which was simulated by the Imma substructure, as already commented. ${ }^{36}$ Our calculations (Fig. 8) show that the $\mathrm{CaFe}_{2} \mathrm{O}_{4}$-type phase is also a competitive HP phase in $\mathrm{CdAl}_{2} \mathrm{~S}_{4}$; however, the lack of observation of the $\mathrm{CaFe}_{2} \mathrm{O}_{4}$-type phase at HP in our spinel-type $\mathrm{CdAl}_{2} \mathrm{~S}_{4}$ sample could be related, as already suggested in Ref. 61, to disorder in our spinel sample. Therefore, these last results point out that the systematics of the 
HP phases of both oxospinels and thiospinels is still a challenge and further work is needed which can complement the phase diagram initiated by Zhang and Zunger. ${ }^{19}$

\section{CONCLUSIONS}

We have performed a joint experimental and theoretical study of the structural and vibrational properties of $\mathrm{CdAl}_{2} \mathrm{~S}_{4}$ at high pressures. Our measurements show that $\mathrm{DC}-\mathrm{CdAl}_{2} \mathrm{~S}_{4}$ undergoes an irreversible order-disorder phase transition to the DR structure between 11-15 GPa and on decreasing pressure from 20-25 GPa it retains the DR structure and eventually reverts to an spinel-type phase. The recovery of the spinel phase is in good agreement with our theoretical calculations that suggest that both spinel and DC phases are competitive stable phases in $\mathrm{CdAl}_{2} \mathrm{~S}_{4}$ near ambient conditions. This result corroborates the crystal-chemical suggestion proposed by Razzetti et al., ${ }^{6}$ in which the properties of DC- $A B_{2} X_{4}$ compounds are given by their binary constituents $\left(A X+B_{2} X_{3}\right)$, being the cation coordination provided by the $A X$ compound and the defect characteristic assumed by the defect structure formed in the $B_{2} X_{3}$ compound. Particularly, DC-CdAl $\mathrm{S}_{4}$ has the defect structure of spinel-type $\mathrm{Al}_{2} \mathrm{~S}_{3}$ and the tetrahedral coordination of wurtzite-type CdS. Note that most $B_{2} X_{3}$ compounds have defective tetrahedral coordination except $\mathrm{Al}_{2} \mathrm{~S}_{3}$ and $\mathrm{In}_{2} \mathrm{~S}_{3}$ which crystallize in a defective spinel structure with octahedral coordination. Therefore, this result makes easy to understand why $A \operatorname{In}_{2} \mathrm{~S}_{4}(\mathrm{~A}=\mathrm{Mg}$, $\mathrm{Cd}, \mathrm{Mn}$ ) crystallize in the spinel structure and why the spinel structure is so competitive in $A \mathrm{Al}_{2} \mathrm{~S}_{4}(\mathrm{~A}=\mathrm{Zn}, \mathrm{Cd})$ at ambient conditions as rationalized by our work and that of Zhang and Zunger. $^{19}$

We have reported the EOS of both DC and DR structures of $\mathrm{CdAl}_{2} \mathrm{~S}_{4}$ which were found to be similar to those found in other $A B_{2} X_{4}$ OVCs. The nature of the Raman-active modes has been 
discussed in relation to the different tetrahedral units of $\mathrm{DC}-\mathrm{CdAl}_{2} \mathrm{~S}_{4}$ and the pressure coefficients of the Raman-active mode frequencies of the DC and spinel phases are reported and found to be similar to those of other $A B_{2} X_{4}$ compounds.

Finally, we have observed that the HP phase of the spinel phase of $\mathrm{CdAl}_{2} \mathrm{~S}_{4}$ seems to be also the DR phase. This could be due to the presence of disorder in the spinel lattice but this hypothesis must be explored in more detail since the $\mathrm{CaFe}_{2} \mathrm{O}_{4}$-type phase has also been found to be competitive at $\mathrm{HP}$ as in the case of $\alpha-\mathrm{ZnAl}_{2} \mathrm{~S}_{4}$. We hope that the present measurements will foster the future growth and measurements of the properties of spinel-type $\mathrm{CdAl}_{2} \mathrm{~S}_{4}$, the study of the relationship between the structures of spinel-type compounds and OVCs, and the systematics of their HP phases.

\section{REFERENCES}

(1) Hahn, H.; Frank, G.; Klinger, W.; Meyer, A. K.; Storger, G. Untersuchungen über Ternäre Chalkogenide. V. Über einige Ternäre Chalkogenide mit Chalkopyritstruktur. Z. Anorg. Allg. Chem. 1953, 271, 153-170.

(2) Goodman, C. H. L.; Douglas, R. W. New Semiconducting Compounds of Diamond Type Structure. Physica 1954, 20, 1107-1109.

(3) Bernard, M. Glances at Ternary Compounds, J. de Physique 1975, Colloque C3, suppl. No 9, 36, C3-1.

(4) Parthe, E. Crystal chemistry of tetrahedral structures 1975, Gordon and Breach, London. 
(5) MacKinnon, A. Tables of Numerical Data and Functional Relationships in Science and Technology 1985, edited by O. Madelung, M. Schulz, and H. Weiss (Springer-Verlag, Berlin) $17,124$.

(6) Razzetti, C.; Lottici, P. P.; Antonioli, G. Structure and Lattice Dynamics of Nonmagnetic Defective $\mathrm{A}^{\mathrm{II}} \mathrm{B}^{\mathrm{III}}{ }_{2} \mathrm{X}^{\mathrm{IV}}{ }_{4}$ Compounds and Alloys. Prog. Cryst. Growth and Character. 1987, 15, 43-73.

(7) Manjón, F.J.; Vilaplana, R. Pressure-Induced Phase Transitions in $\mathrm{AB}_{2} \mathrm{X}_{4}$ Chalcogenide Compounds 2014, Springer Series in Materials Science, edited by F.J. Manjón, I. Tiginyanu and V Ursaki (Springer, Berlin), 189, 133.

(8) Gomis, O.; Manjón, F.J. Pressure-Induced Phase Transitions in $\mathrm{AB}_{2} \mathrm{X}_{4}$ Chalcogenide Compounds 2014, Springer Series in Materials Science, edited by F.J. Manjón, I. Tiginyanu and V Ursaki (Springer, Berlin), 189, 163.

(9) Muñoz, A.; Fuentes-Cabrera, M. Pressure-Induced Phase Transitions in $\mathrm{AB}_{2} \mathrm{X}_{4}$ Chalcogenide Compounds 2014, Springer Series in Materials Science, edited by F.J. Manjón, I. Tiginyanu and V Ursaki (Springer, Berlin), 189, 185.

(10) Errandonea, D.; Kumar, R.S.; Gomis, O.; Manjón, F.J.; Ursaki, V.V.; Tiginyanu, I.M. XRay Diffraction Study on Pressure-Induced Phase Transformations and the Equation of State of $\mathrm{ZnGa}_{2} \mathrm{Te}_{4}$. J. Appl. Phys. 2013, 114, 233507-1-233507-7.

(11) Burlakov, I.I.; Raptis, Y.; Ursaki, V.V.; Anastassakis, E.; Tiginyanu, I.M. Order-Disorder Phase Transition in $\mathrm{CdAl}_{2} \mathrm{~S}_{4}$ under Hydrostatic Pressure. Solid State Commun. 1997, 101, $377-$ 381. 
(12) Fuentes-Cabrera, M. Ab Initio Study of the Vibrational and Electronic Properties of $\mathrm{CdGa}_{2} \mathrm{~S}_{4}$ and $\mathrm{CdGa}_{2} \mathrm{Se}_{4}$ under Pressure. J. Phys.: Condens. Matter 2001, 13, 10117-10124.

(13) Meenakshi, S.; Vijyakumar, V.; Godwal, B.K.; Eifler, A.; Orgzall, I.; Tkachev, S.; Hochheimer, H.D. High pressure X-Ray Diffraction Study of $\mathrm{CdAl}_{2} \mathrm{Se}_{4}$ and Raman Study of $\mathrm{AAl}_{2} \mathrm{Se}_{4}(\mathrm{~A}=\mathrm{Hg}, \mathrm{Zn})$ and $\mathrm{CdAl}_{2} \mathrm{X}_{4}(\mathrm{X}=\mathrm{Se}, \mathrm{S})$. J. Phys. Chem. Solids 2006, 67, 1660-1667.

(14) Errandonea, D.; Kumar, R.S.; Manjón, F.J.; Ursaki, V.V.; Tiginyanu, I.M. High-Pressure X-Ray Diffraction Study on the Structure and Phase Transitions of the Defect-Stannite $\mathrm{ZnGa}_{2} \mathrm{Se}_{4}$ and Defect-Chalcopyrite $\mathrm{CdGa}_{2} \mathrm{~S}_{4}$. J. Appl. Phys. 2008, 104, 063524-1-063524-9.

(15) Meenakshi, S.; Vijayakumar, V.; Eifler, A.; Hoch-heimer, H. D. Pressure-Induced Phase Transition in Defect Chalcopyrites $\mathrm{HgAl}_{2} \mathrm{Se}_{4}$ and $\mathrm{CdAl}_{2} \mathrm{~S}_{4}$. J. Phys. Chem. Solids 2010, 71, 832835.

(16) Jiang, X.S.; Yan, Y.C.; Yuan, S.M.; Mi, S.; Niu, Z.G.; Liang, J.Q. Trends in the BandGap Pressure Coefficients and Bulk Moduli in Different Structures of $\mathrm{ZnGa}_{2} \mathrm{~S}_{4}, \mathrm{ZnGa}_{2} \mathrm{Se}_{4}$ and $\mathrm{ZnGa}_{2} \mathrm{Te}_{4}$. Chin. Phys. B 2010, 19, 107104-1-107104-8.

(17) Vilaplana, R.; Robledillo, M.; Gomis, O.; Sans, J.A.; Manjón, F.J.; Pérez-González, E.; Rodríguez-Hernández, P.; Muñoz, A.; Tiginyanu, I.M.; Ursaki, V.V. Vibrational Study of $\mathrm{HgGa}_{2} \mathrm{~S}_{4}$ under High Pressure. J. Appl. Phys. 2013, 113, 093512-1-093512-1.

(18) Gomis, O.; Santamaría-Pérez, D.; Vilaplana, R.; Luna, R.; Sans, J.A.; Manjón, F.J.; Errandonea, D.; Pérez-González, E.; Rodríguez-Hernández, P.; Muñoz A.; et al. Structural and Elastic Properties of Defect Chalcopyrite $\mathrm{HgGa}_{2} \mathrm{~S}_{4}$ under High Pressure. J. Alloy Comp. 2013, 583, 70-78. 
(19) Zhang, X.; Zunger, A. Diagrammatic Separation of Different Crystal Structures of $\mathrm{A}_{2} \mathrm{BX}_{4}$ Compounds Without Energy Minimization: A Pseudopotential Orbital Radii Approach. Adv. Funct. Mater 2010, 20, 1944-1952.

(20) Schwer, H.; Kramer, V. The Crystal-Structures of $\mathrm{CdAl}_{2} \mathrm{~S}_{4}, \mathrm{HgAl}_{2} \mathrm{~S}_{4}$, and $\mathrm{HgGa}_{2} \mathrm{~S}_{4}$. Z. Kristall. 1990, 190, 103-110.

(21) Tiginyanu, I.M.; Moldovyan, N. A.; Stoika, O. D. Phonon-Spectrum and Band Edge Absorption in $\mathrm{CdAl}_{2} \mathrm{~S}_{4}$. Fiz. Tverd. Tela 1992, 34, 967-969.

(22) Klotz, S.; Chervin, J.C.; Munsch, P.; Le Marchand, G. Hydrostatic Limits of 11 Pressure Transmitting Media. J. Phys. D 2009, 42, 075413-1-075413-7.

(23) Errandonea, D.; Meng, Y.; Somayazulu, M.; Hausermann, D. Pressure-Induced Image Transition in Titanium Metal: A Systematic Study of the Effects of Uniaxial Stress. Physica B 2005, 355, 116-125.

(24) Fauth, F.; Peral, I.; Popescu, C.; Knapp, M. The New Material Science Powder Diffraction Beamline at ALBA Synchrotron. Powder Diffraction 2013, 28, S360-S370.

(25) Mao, H. K.; Xu, J.; Bell, P. M. Calibration of the Ruby Pressure Gauge to 800 Kbar under Quasi-Hydrostatic Conditions. J. Geophys. Res. 1986, 91, 4673-4676.

(26) Syassen, K. Ruby under Pressure. High Press. Res. 2008, 28, 75-126.

(27) Dewaele, A.; Loubeyre, P.; Mezouar, M. Equations of State of Six Metals above 94 GPa. Phys. Rev. B 2004, 70, 094112-1-094112-8. 
(28) Rodriguez-Carvajal, J. Recent Advances in Magnetic Structure Determination by Neutron Powder Diffraction. Physica B 1993, 192, 55-69.

(29) Toby, B. H. EXPGUI, a Graphical User Interface for GSAS. J. Appl. Cryst. 2001, 34, 210213.

(30) Kresse, G. computer code VASP; see http://www.vasp.at

(31) Perdew, J.P.; Ruzsinszky, A.; Csonka, G.I.; Vydrov, O.A.; Scuseria, G.E.; Constantin, L.A.; Zhou, X.; Burke, K. Restoring the Density-Gradient Expansion for Exchange in Solids and Surfaces. Phys. Rev. Lett. 2008, 100, 136406-1-136406-4.

(32) Kresse, G.; Joubert, D. From Ultrasoft Pseudopotentials to the Projector AugmentedWave Method. Phys. Rev. B 1999, 59, 1758-1775.

(33) Manjón, F.J.; Gomis, O.; Rodríguez-Hernández, P.; Pérez-González, E.; Muñoz, A.; Errandonea, D.; Ruiz-Fuertes, J.; Segura, A.; Fuentes-Cabrera, M.; Tiginyanu, I.M.; et al. Nonlinear Pressure Dependence of the Direct Band Gap in Adamantine Ordered-Vacancy Compounds. Phys. Rev. B 2010, 81, 195201-1-195201-7.

(34) Gomis, O.; Vilaplana, R.; Manjón, F.J.; Pérez-González, E.; López-Solano, J.; RodríguezHernández, P.; Muñoz, A.; Errandonea, D.; Ruiz-Fuertes, J.; Segura, A.; et al. High-Pressure Optical and Vibrational Properties of $\mathrm{CdGa}_{2} \mathrm{Se}_{4}$ : Order-Disorder Processes in Adamantine Compounds. J. Appl. Phys. 2012, 111, 013518-1-013518-15.

(35) Gomis, O.; Vilaplana, R.; Manjón, F. J.; Santamaría-Pérez, D.; Errandonea, D.; PérezGonzález, E.; López-Solano, J.; Rodríguez-Hernández, P.; Muñoz, A.; Tiginyanu, I.M.; et al. 
High-Pressure Study of the Structural and Elastic Properties of Defect Chalcopyrite $\mathrm{HgGa}_{2} \mathrm{Se}_{4} . J$. Appl. Phys. 2013, 113, 073510-1-073510-10.

(36) Santamaría-Pérez, D.; Amboage, M.; Manjón, F.J.; Errandonea, D.; Muñoz, A.; Rodríguez-Hernández, P.; Mujica, A.; Radescu, S.; Ursaki, V.V.; Tiginyanu, I.M. Crystal Chemistry of $\mathrm{CdIn}_{2} \mathrm{~S}_{4}, \mathrm{MgIn}_{2} \mathrm{~S}_{4}$, and $\mathrm{MnIn}_{2} \mathrm{~S}_{4}$ Thiospinels under High Pressure. J. Phys. Chem. C 2012, 116, 14078-14087.

(37) López-Moreno, S.; Rodríguez-Hernández, P.; Muñoz, A.; Romero, A.H.; Manjón, F.J.; Errandonea, D.; Rusu, E.; Ursaki, V.V. Lattice Dynamics of $\mathrm{ZnAl}_{2} \mathrm{O}_{4}$ and $\mathrm{ZnGa}_{2} \mathrm{O}_{4}$ under High Pressure Ann. Phys. 2011, 523, 157-167.

(38) Mujica, A.; Rubio, A.; Muñoz, A.; Needs, R.J. High-Pressure Phases of Group-IV, III-V, and II-VI Compounds. Rev. Mod. Phys. 2003, 75, 863-912.

(39) Baroni, S.; de Gironcoli, S.; del Corso, A.; Giannozzi, P. Phonons and Related Crystal Properties from Density-Functional Perturbation Theory. Rev. Mod. Phys. 2001, 73, 515-562.

(40) Giannozzi, P.; Baroni, S.; Bonini, P.; Calandra, M.; Car, R.; Cavazzoni, C.; Ceresoli, D.; Chiarotti, G. L.; Cococcioni, M.; Dabo, I.; et al. QUANTUM ESPRESSO: a Modular and OpenSource Software Project for Quantum Simulations of Materials J. Phys.:Condens. Matter 2009, 21, 395502-1-395502-19.

(41) Vilaplana, R.; Gomis, O.; Pérez-González, E.; Ortiz, H.M.; Manjón, F.J.; RodríguezHernández, P.; Muñoz, A.; Alonso-Gutiérrez, P.; Sanjuán, M.L.; Ursaki, V.V.; Tiginyanu, I.M. Thermally Activated Cation Ordering in $\mathrm{ZnGa}_{2} \mathrm{Se}_{4}$ Single Crystals Studied by Raman Scattering, 
Optical Absorption, and Ab Initio Calculations. J. Phys: Condens. Matter 2013, 25, 165802-1$165802-11$

(42) Grzechnik, A.; Ursaki, V.V.; Syassen, K.; Loa, I.; Tiginyanu, I.M.; Handfland, M. Pressure-Induced Phase Transitions in Cadmium Thiogallate $\mathrm{CdGa}_{2} \mathrm{Se}_{4}$. J. Solid State Chem. 2001, 160, 205-211.

(43) Marquina, J.; Power, Ch.; Grima, P.; Morocoima, M.; Quintero, M.; Couzinet, B.; Chervin, J.C.; Munsch, P.; González, J. Crystallographic Properties of the $\mathrm{MnGa}_{2} \mathrm{Se}_{4}$ Compound under High Pressure. J. Appl. Phys. 2006, 100, 093513-1-093513-6.

(44) Gomis, O.; Vilaplana, R.; Manjón, F.J.; Santamaría-Pérez, D.; Errandonea, D.; PérezGonzález, E.; López-Solano, J.; Rodríguez-Hernández, P.; Muñoz, A.; Tiginyanu, I.M.; et al. Crystal Structure of $\mathrm{HgGa}_{2} \mathrm{Se}_{4}$ under Compression. Mat. Res. Bull. 2013, 48, 2128-2133.

(45) Robinson, K.; Gibbs, G. V.; Ribbe, P. H. Quadratic Elongation: A Quantitative Measure of Distortion in Coordination Polyhedra. Science 1971, 172, 567-570.

(46) Sowa, H. On the Mechanism of the Pressure-Induced Wurtzite- to NaCl-type Phase Transition in CdS: an X-Ray Diffraction Study. Solid State Sciences 2005, 7, 73-78.

(47) Tiginyanu, I.M.; Ursaki, V.V.; Manjon, F.J.; Tezlevan, V.E. Raman Scattering Study of Pressure-Induced Phase Transitions in $\mathrm{A}^{\mathrm{II}} \mathrm{B}_{2}{ }^{\mathrm{III}} \mathrm{C}_{4}{ }^{\mathrm{VI}}$ Defect Chalcopyrites and Spinels. J. Phys. Chem. Sol. 2003, 64, 1603-1607.

(48) Kroumova, E.; Aroyo, M.I.; Perez-Mato, J.M.; Kirov, A.; Capillas, C.; Ivantchev, S.; Wondratschek, H. Bilbao Crystallographic Server: Useful Databases and Tools for Phase Transitions Studies. Phase Transitions 2003, 76, 155-170. 
(49) Guittard, M.; Chilouet, A.; Palazzi, M.; Pardo, M.P. $\mathrm{Y}_{2} \mathrm{~S}_{3}-\mathrm{Al}_{2} \mathrm{~S}_{3}$ Phases Diagram. Comparison with $\mathrm{Y}_{2} \mathrm{~S}_{3}-\mathrm{M}_{\mathrm{x}} \mathrm{S}_{\mathrm{y}}, \mathrm{M}=\mathrm{Ga}$, In, $\mathrm{Tl}(\mathrm{x}=2, \mathrm{y}=3$ or 1). Mat. Res. Bull. 1991, 26, 707-713.

(50) Canepa, P.; Hanson, R. M.; Ugliengo, P.; Alfredsson, M. J-ICE: A New Jmol Interface for Handling and Visualizing Crystallographic and Electronic Properties. J. Appl. Cryst. 2011, 44, 225-229.

(51) Razzetti, C.; Lottici, P.P. Effects of the Cations on the Raman-Spectra of Sulfur Defect Chalcopyrites. Jpn. J. Appl. Phys. 1993, 32, 431-435.

(52) Eifler, A.; Hecht, J-D.; Riede, V.; Lippold, G.; Schmitz, W.; Krauss, G.; Krämer, V.; Grill, W. Infrared and Raman Study of Lattice Vibrations of $\mathrm{CdAl}_{2} \mathrm{Se}_{4}$ and $\mathrm{CdAl}_{2} \mathrm{~S}_{4}$ Single Crystals. J. Phys. Condens. Matter 1999, 11, 4821-4832.

(53) Manjón, F.J.; Gomis, O.; Vilaplana, R.; Sans J.A.; Ortiz, H.M. Order-Disorder Processes in Adamantine Ternary Ordered-Vacancy Compounds. Phys. Stat. Sol. (b) 2013, 250, 14961504.

(54) Vilaplana, R.; Gomis, O.; Manjón, F.J.; Ortiz, H.M.; Pérez-González, E.; López-Solano, J.; Rodríguez-Hernández, P.; Muñoz, A.; Errandonea, D.; Ursaki, V.V.; et al. Lattice Dynamics Study of $\mathrm{HgGa}_{2} \mathrm{Se}_{4}$ at High Pressures. J. Phys. Chem. C 2013, 117, 15773-15781.

(55) Vilaplana, R.; Gomis, O.; Pérez-González, E.; Ortiz, H.M.; Manjón, F.J.; RodríguezHernández, P.; Muñoz, A.; Alonso-Gutiérrez, P.; Sanjuán, M.L.; Ursaki, V.V.; Tiginyanu, I.M. High-Pressure Raman Scattering Study of Defect Chalcopyrite and Defect Stannite $\mathrm{ZnGa}_{2} \mathrm{Se}_{4}$. J. Appl. Phys. 2013, 113, 233501-1-233501-10. 
(56) Ibáñez, J.; Oliva, R.; Manjón, F.J.; Segura, A.; Yamaguchi, T.; Nanishi, Y.; Cuscó, R.; Artús, L. High-Pressure Lattice Dynamics in Wurtzite and Rocksalt Indium Nitride Investigated by means of Raman Spectroscopy. Phys. Rev. B 2013, 88, 115202-1-115202-13.

(57) Marinelli, M.; de Pascale, T.M.; Meloni, F.; Mula, G.; Serra, M.; Baroni, S. Theoretical Study of Cubic versus Tetragonal Structures of Defect Zinc-Blende Semiconductors: $\mathrm{CdIn}_{2} \mathrm{Se}_{4}$. Phys. Rev. B 1989, 40, 1725-1731.

(58) Range, K.J.; Becker, W.; Weiss, A. High Pressure Phases of $\mathrm{CdAl}_{2} \mathrm{~S}_{4} \mathrm{HgAl}_{2} \mathrm{~S} 4 \mathrm{ZnAl}_{2} \mathrm{Se}_{2}$ $\mathrm{CdAl}_{2} \mathrm{Se}_{4}$ and $\mathrm{HgAl}_{2} \mathrm{Se}_{4}$ with a Spinel Structure. Z. Naturforsch. 1968, 23b, 1009.

(59) Hills, M.E.; Harris, D.C.; Lowe-Ma, C.K. Zinc Aluminum Sulfide: Electron Paramagnetic Resonance Spectroscopy and Infrared Transmittance. J. Phys. Chem Solids 1987, 48, 501-507.

(60) Moldovyan, N.A. Growth and Photoconductivity of $\mathrm{ZnAl}_{2} \mathrm{~S}_{4}$ and $\mathrm{CdAl}_{2} \mathrm{~S}_{4}$ Crystals. Izv. Akad. Nauk. SSSR, Neorg. Mater. 1991, 27, 1667-1669.

(61) Ursaki, V.V.; Burlakov, I.I.; Tiginyanu, I.M.; Raptis, Y.S.; Anastassakis, E.; Aksenov, I.; Sato, K. Pressure Induced Phase Transitions in Spinel and Wurtzite Phases of $\mathrm{ZnAl}_{2} \mathrm{~S}_{4}$ Compound. Jpn. J. Appl. Phys. 1998, 37, 135-140. 
FIGURES

(a)

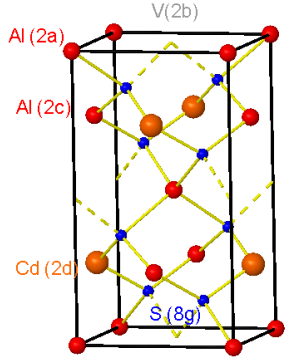

(b)

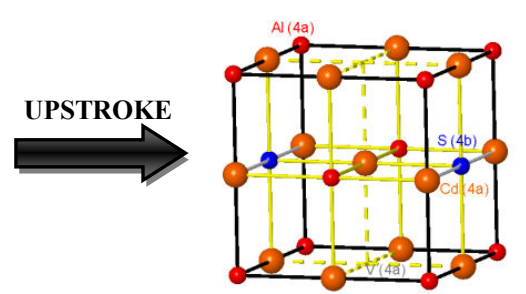

(c)
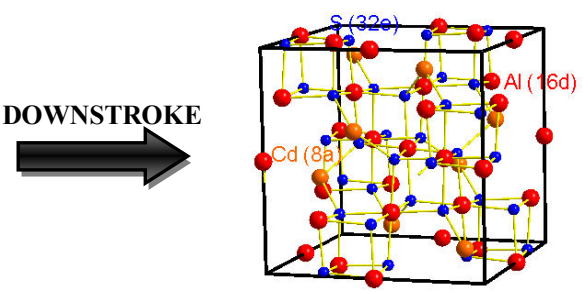

Figure 1. (color online) Representation of the crystalline structures in $\mathrm{CdAl}_{2} \mathrm{~S}_{4}$ : Defect chalcopyrite (a), Disordered-Rocksalt (b) and Cubic Spinel (c). 


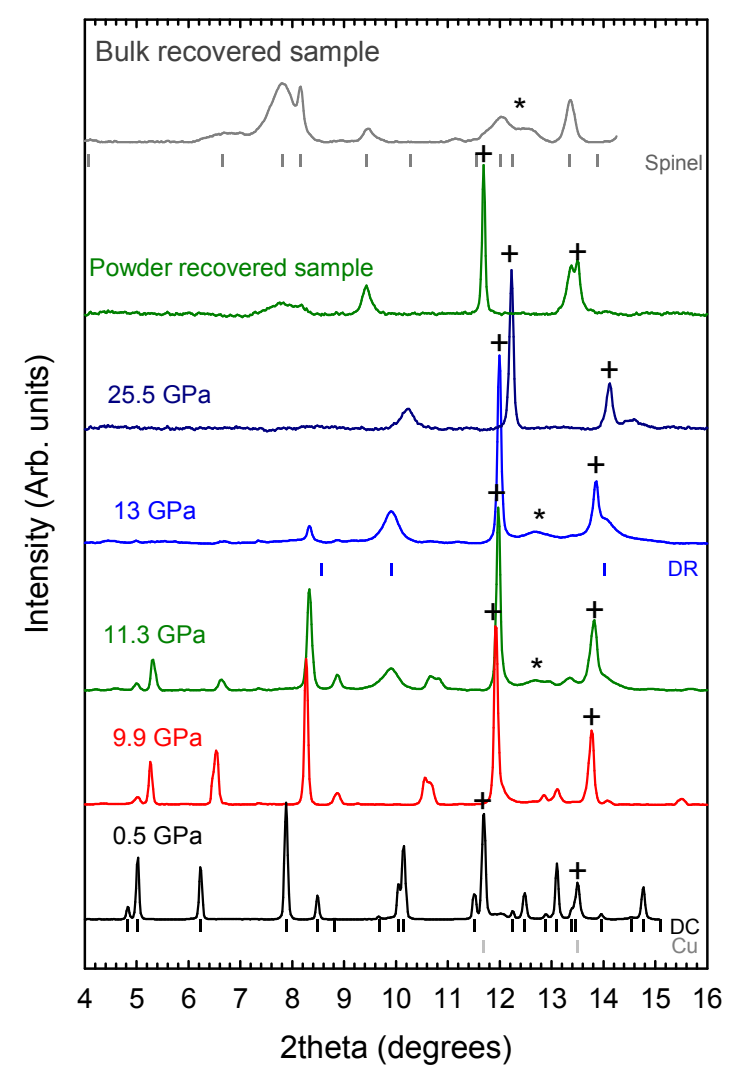

Figure 2. (color online) Powder XRD patterns of $\mathrm{CdAl}_{2} \mathrm{~S}_{4}$ at selected pressures. The upper patterns correspond to the recovered sample after decompression in powder and singlecrystalline sample. Asterisks indicate the position of the most intense gasket peak and the cross the position of the $\mathrm{Cu}$ peaks. Vertical markers at $0.5 \mathrm{GPa}$ show the Bragg reflections of the DC$\mathrm{CdAl}_{2} \mathrm{~S}_{4}$ structure (top) and $\mathrm{Cu}$ (bottom). Vertical marks at $13 \mathrm{GPa}$ correspond to HP-DR phase and the vertical marks below the pattern of the bulk-recovered sample corresponds to the spinel structure. 


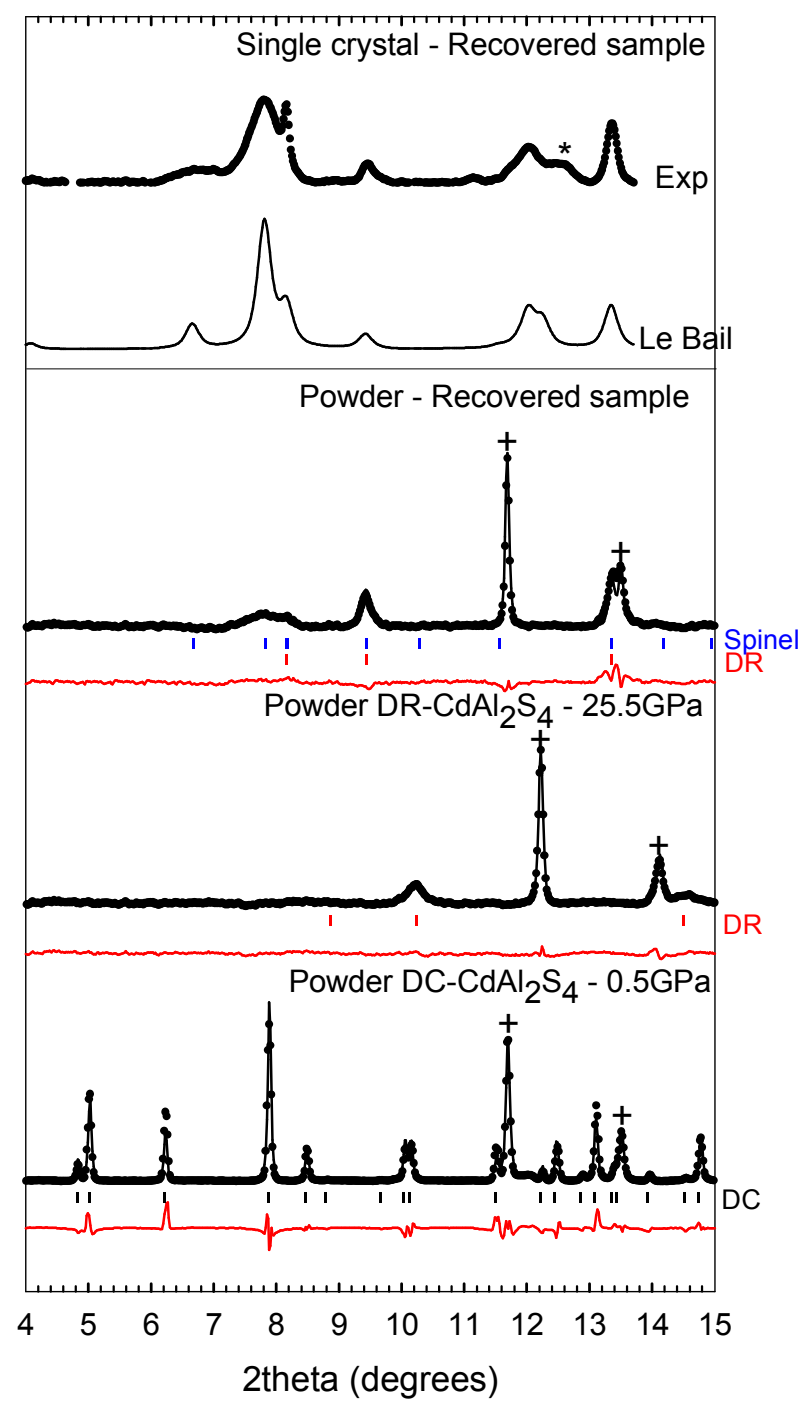

Figure 3. (color online) Experimental XRD patterns and Rietveld refinements of several phases observed in $\mathrm{CdAl}_{2} \mathrm{~S}_{4}$. Crosses indicate the position of the $\mathrm{Cu}$ peaks and asterisk the gasket signal. Residuals of the Rietveld refinements are plotted below the experimental (circles) and fitted (lines) XRD profiles (except for the single-crystal recovered sample where we performed a Le Bail refinement). 

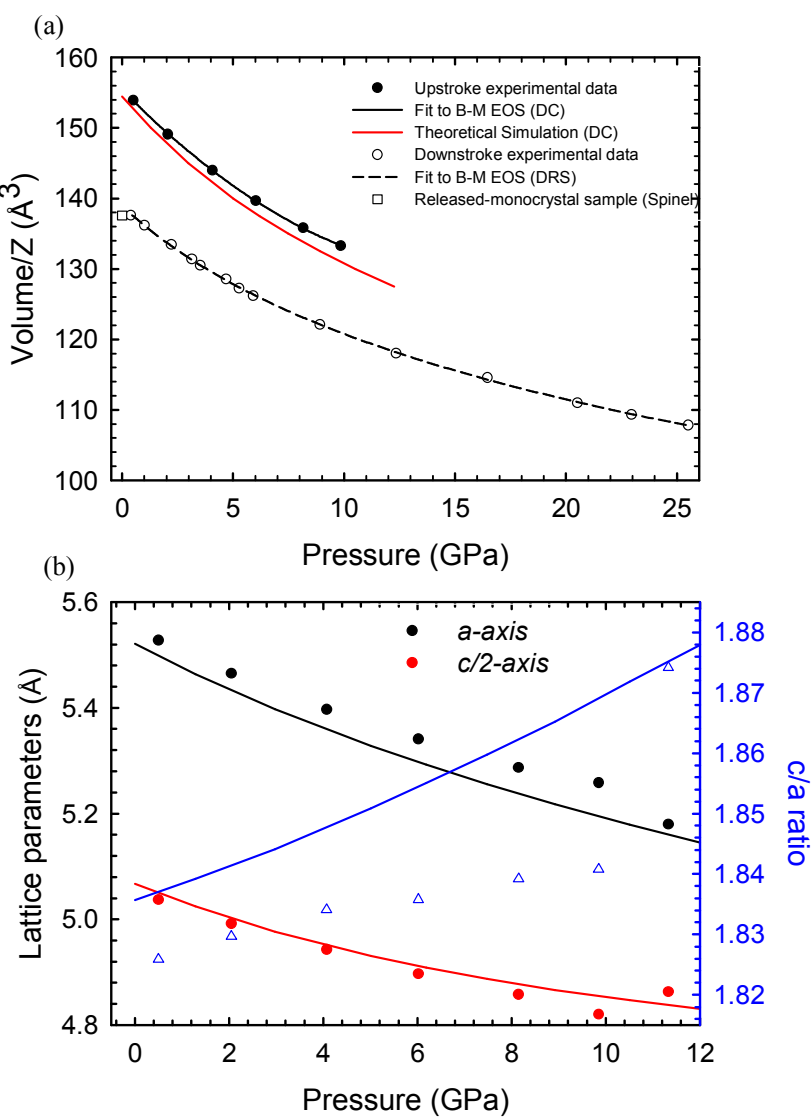

Figure 4. (color online) (a) Pressure dependence of the volume per formula unit for $\mathrm{CdAl}_{2} \mathrm{~S}_{4}$. (b) Left: Evolution of the $a$ (circles) and $c$ (square) lattice parameters of the DC-structure $\mathrm{CdAl}_{2} \mathrm{~S}_{4}$ with pressure. Right: $c / a$ axes ratio (triangles) vs pressure. 


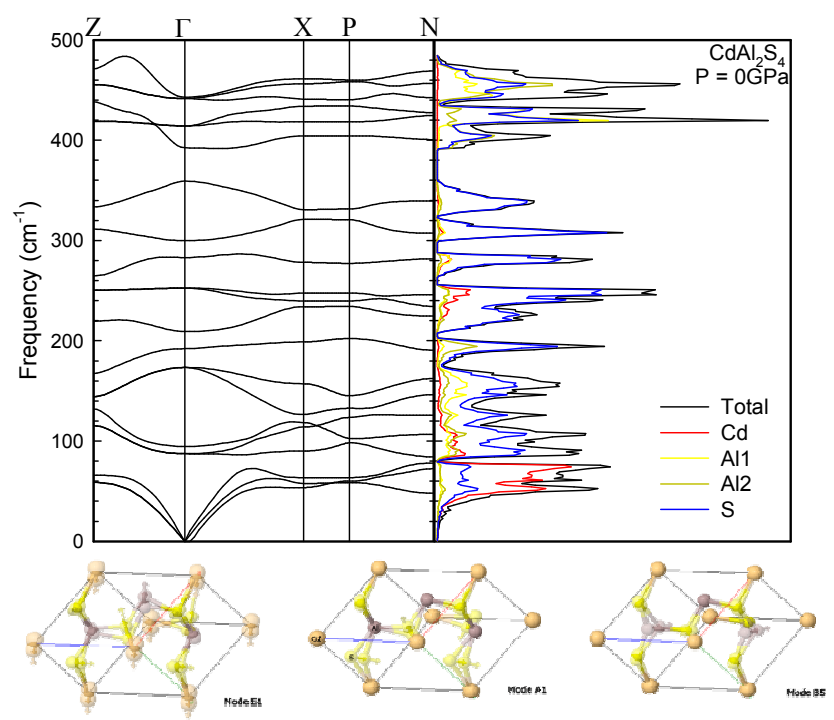

Figure 5. (color online) Phonon dispersion curves and projected phonon density of states in $\mathrm{CdAl}_{2} \mathrm{~S}_{4}$ at 1 atm. Bottom: graphical representation of vibrating atoms corresponding to representative Raman modes of low-, medium-, and high-frequency region. 

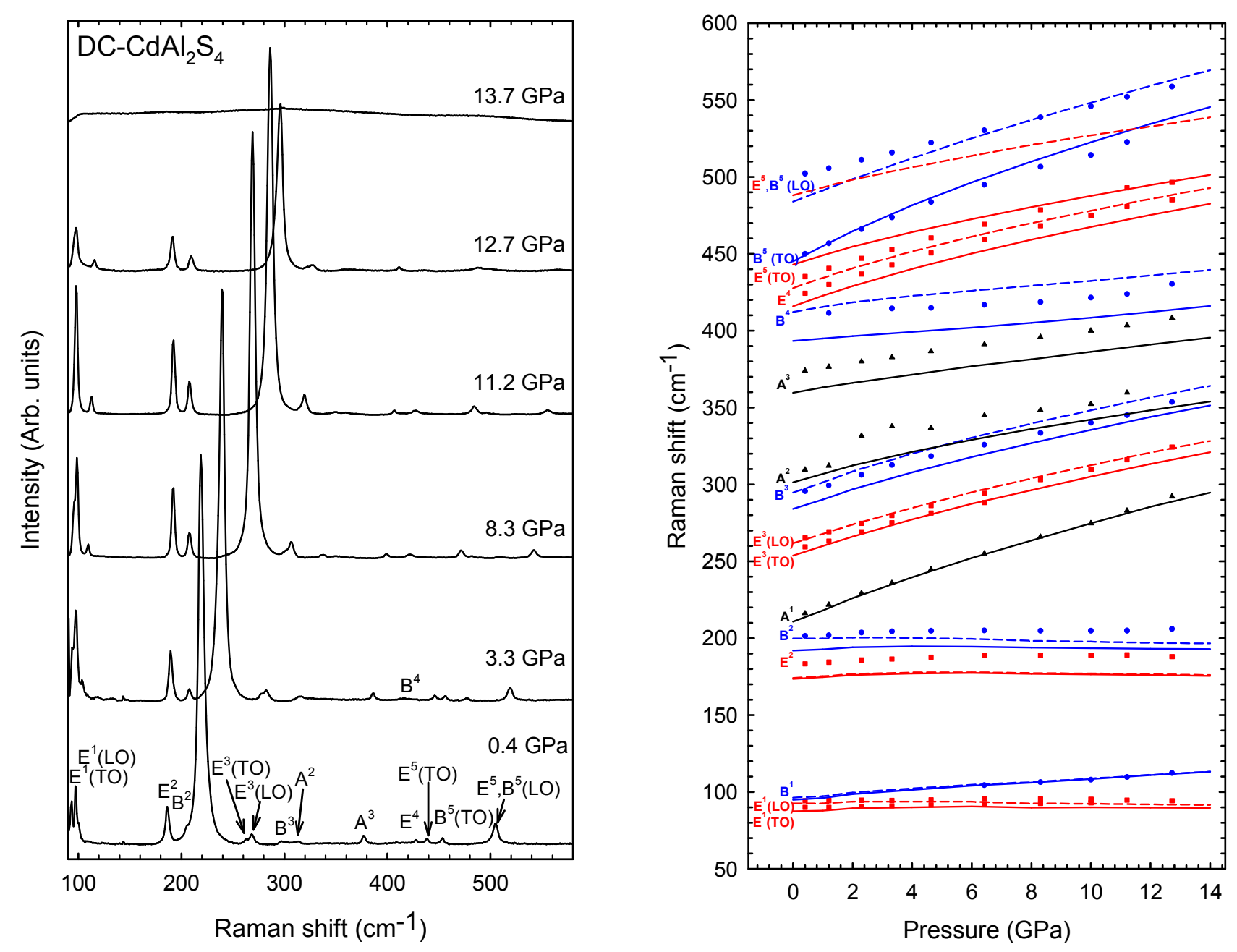

Figure 6. (Color online) (a) Ambient temperature RS spectra of $\mathrm{DC}-\mathrm{CdAl}_{2} \mathrm{~S}_{4}$ up to $15 \mathrm{GPa}$. (b) Pressure dependence of calculated (lines) and experimental (symbols) vibrational modes in DC$\mathrm{CdAl}_{2} \mathrm{~S}_{4}$. Experimental values of $\mathrm{A}, \mathrm{B}_{\mathrm{TO}} / \mathrm{B}_{\mathrm{LO}}$ and $\mathrm{E}_{\mathrm{TO}} / \mathrm{E}_{\mathrm{LO}}$ Raman modes are represented by solid triangles (black), solid/open circles (blue), and solid/open squares (red), respectively. 

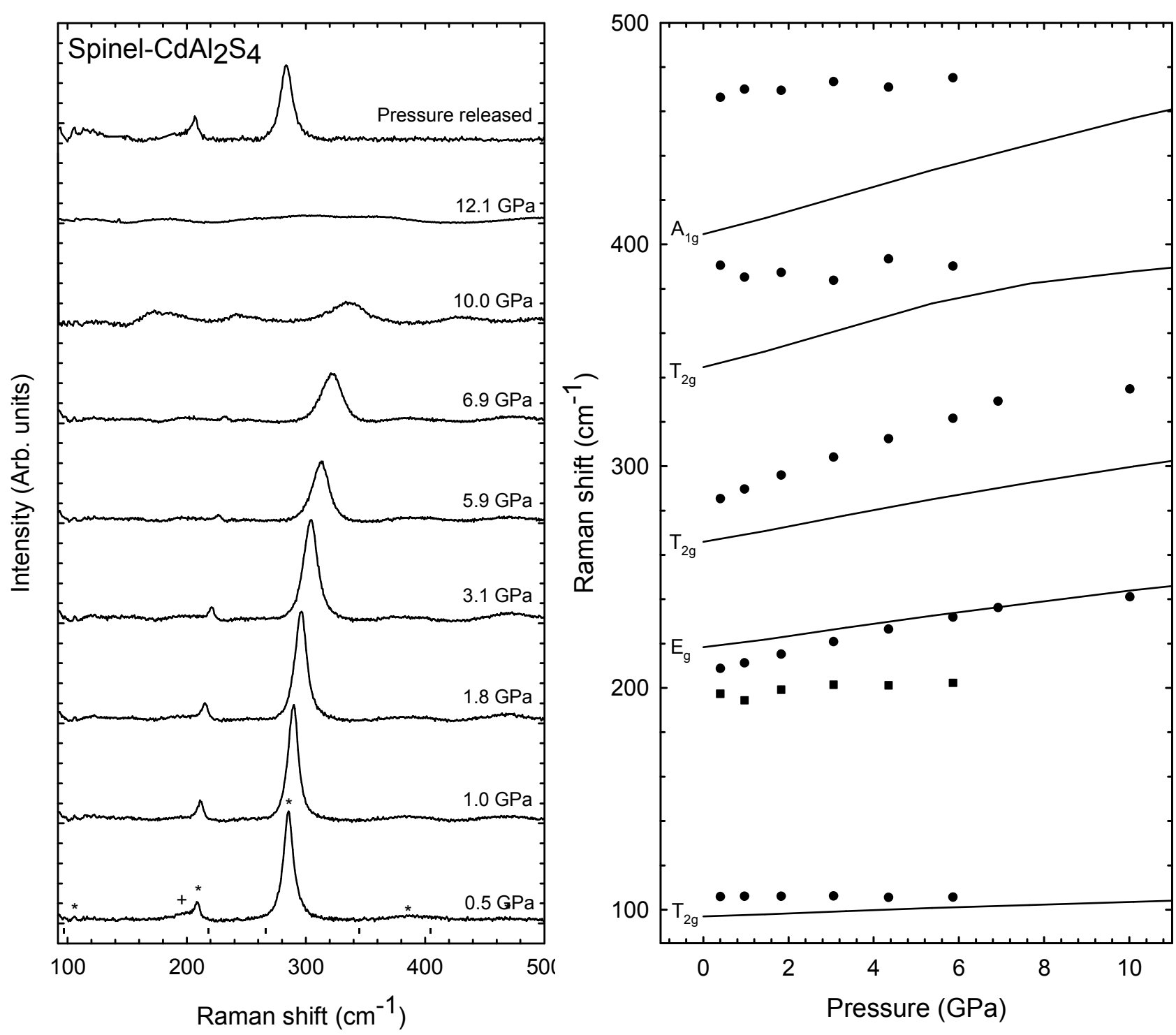

Figure 7. (Color online) (a) Ambient temperature RS spectra of spinel-type $\mathrm{CdAl}_{2} \mathrm{~S}_{4}$ up to 15 GPa. Asterisks indicate the Raman modes and the cross indicates a possible second-order feature. (b) Pressure dependence of theoretical (lines) and experimental (symbols) vibrational modes in spinel-type $\mathrm{CdAl}_{2} \mathrm{~S}_{4}$. 


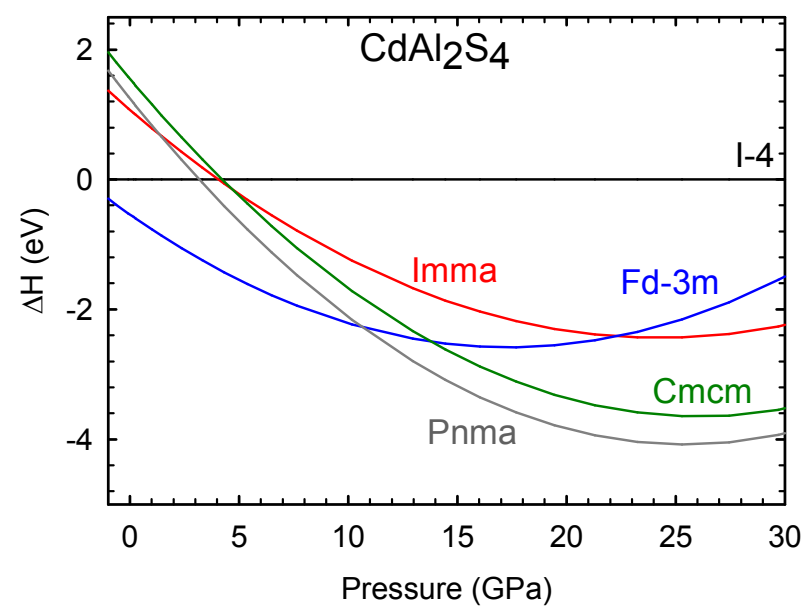

Figure 8. (Color online) Enthalpy difference vs. pressure, referred to the DC (I-4) of: spinel (Fd$3 \mathrm{~m})$, defect-LiTiO 2 -type (Imma), $\mathrm{CaFe}_{2} \mathrm{O}_{4}$-type (Pnma), $\mathrm{CaTi}_{2} \mathrm{O}_{4}$-type $(\mathrm{Cmcm})$, and $\mathrm{CaMn}_{2} \mathrm{O}_{4}$ type $(\mathrm{Pbcm})$ phases in $\mathrm{CdAl}_{2} \mathrm{~S}_{4}$. The enthalpy of the $\mathrm{CaMn}_{2} \mathrm{O}_{4}$-type and $\mathrm{CaTi}_{2} \mathrm{O}_{4}$-type phases are equal so only one is plotted. 
TABLES.

\begin{tabular}{|l|l|l|l|}
\hline & Experiment & Calculations & Experiment (Ref. 20) \\
\hline$a(\AA)$ & $5.5396(2)$ & 5.5211 & $5.5523(1)$ \\
\hline$c(\AA)$ & $10.0758(8)$ & 10.1350 & $10.1031(2)$ \\
\hline $\mathrm{xS}$ & $0.2743(15)$ & 0.26901 & $0.2660(1)$ \\
\hline $\mathrm{yS}$ & $0.260(2)$ & 0.27222 & $0.2770(1)$ \\
\hline $\mathrm{zS}$ & $0.1337(7)$ & 0.13655 & $0.1352(1)$ \\
\hline
\end{tabular}

Table 1. Lattice parameters and atomic coordinates of the $S$ atom at ambient temperature from our powder XRD experiment and theoretical calculations on $\mathrm{DC}-\mathrm{CdAl} \mathrm{S}_{4}$ compared to those of literature (Ref. 20). 


\begin{tabular}{|c|c|c|c|c|c|c|c|c|c|}
\hline $\begin{array}{l}\text { Mode } \\
\text { Sym. }\end{array}$ & $\begin{array}{l}\omega_{0} \\
(\text { th. }) \\
\left(\mathrm{cm}^{-1}\right)\end{array}$ & $\begin{array}{l}\text { a } \\
\text { (th.) } \\
\left(\mathrm{cm}^{-1}\right. \\
\left.\mathrm{GPa}^{-1}\right)\end{array}$ & $\begin{array}{l}\mathrm{b} \\
\text { (th.) } \\
\left(10^{-2} \mathrm{~cm}^{-1}\right. \\
\left.\mathrm{GPa}^{-2}\right)\end{array}$ & $\begin{array}{l}\omega_{0} \\
(\text { exp. }) \\
\left(\mathrm{cm}^{-1}\right)\end{array}$ & $\begin{array}{l}\text { a } \\
(\text { exp. }) \\
\left(\mathrm{cm}^{-1}\right. \\
\left.\mathrm{GPa}^{-1}\right) \\
\end{array}$ & $\begin{array}{l}\mathrm{b} \\
(\exp .) \\
\left(10^{-2} \quad \mathrm{~cm}^{-1}\right. \\
\left.\mathrm{GPa}^{-2}\right)\end{array}$ & $\begin{array}{l}\omega_{0}^{\text {Ref. } 11} \\
(\text { exp.) } \\
\left(\mathrm{cm}^{-1}\right)\end{array}$ & $\begin{array}{l}\mathrm{a}^{\text {Ref. } 11} \\
(\text { exp.) } \\
\left(\mathrm{cm}^{-1}\right. \\
\left.\mathrm{GPa}^{-1}\right) \\
\end{array}$ & $\begin{array}{l}\mathrm{b}^{\text {Ref. } 11} \\
\text { (exp.) } \\
\left(10^{-2} \mathrm{~cm}^{-1} \mathrm{GPa}^{-2}\right)\end{array}$ \\
\hline $\mathrm{E}^{1}(\mathrm{TO})$ & $87.7(3)$ & $0.64(9)$ & $-3.8(3)$ & $89.8(2)$ & $0.38(3)$ & $0.01(2)$ & 92 & 0.99 & -5.27 \\
\hline$E^{1}(\mathrm{LO})$ & $92.9(3)$ & $0.22(3)$ & $-2.4(2)$ & $94.1(2)$ & $0.25(3)$ & $-1.1(4)$ & & & \\
\hline $\begin{array}{l}\mathrm{B}^{1}(\mathrm{TO}) \\
\mathrm{B}^{1}(\mathrm{LO})\end{array}$ & 95.1(4) & $1.46(4)$ & $\begin{array}{l}-2.5(2) \\
-1.9(2)\end{array}$ & $94.9(1)$ & $1.5(2)$ & $-1.3(5)$ & 98 & 1.87 & -3.74 \\
\hline $\mathrm{E}^{2}(\mathrm{LO})$ & $174.7(7)$ & $0.82(5)$ & $-5.4(2)$ & $182.9(6)$ & $1.38(9)$ & $-7.6(8)$ & 184 & 1.72 & -9.64 \\
\hline $\begin{array}{l}\mathrm{B}^{2}(\mathrm{TO}) \\
\mathrm{B}^{2}(\mathrm{LO})\end{array}$ & $192.5(5)$ & $-0.02(4)$ & $-3.9(3)$ & $201.6(5)$ & $0.78(6)$ & $-4.0(7)$ & 205 & 0.87 & -5.38 \\
\hline$A^{1}$ & 211.5(4) & $7.49(15)$ & $-1.1(2)$ & $214.0(1)$ & $6.7(1)$ & $-4.6(8)$ & 216 & 7.54 & -13.4 \\
\hline $\mathrm{E}^{3}(\mathrm{TO})$ & 254.1(1) & $6.06(13)$ & $-9.3(5)$ & $256.6(6)$ & $6.08(18)$ & $-17.6(9)$ & 260 & 5.86 & -9.85 \\
\hline $\mathrm{E}^{3}(\mathrm{LO})$ & 262.1(1) & $5.99(13)$ & $-9.1(5)$ & $263.6(3)$ & $4.83(5)$ & $-1.0(8)$ & 266 & 5.86 & -7.84 \\
\hline $\begin{array}{l}\mathrm{B}^{3}(\mathrm{TO}) \\
\mathrm{B}^{3}(\mathrm{LO})\end{array}$ & $\begin{array}{l}284.5(5) \\
295.2(3)\end{array}$ & $\begin{array}{l}6.11(14) \\
6.5(17)\end{array}$ & $\begin{array}{l}-9.6(5) \\
-11.7(5)\end{array}$ & 294.1(8) & $5.34(11)$ & $-6.2(7)$ & 297 & 5.86 & -7.1 \\
\hline $\mathrm{A}^{2}$ & $301.9(8)$ & $5.10(15)$ & $-10.1(5)$ & $308(2)$ & $8.3(1)$ & $-35.9(12)$ & 311 & 0.581 & -7.10 \\
\hline $\mathrm{A}^{3}$ & $360.0(4)$ & $2.97(5)$ & $-3.1(6)$ & $373(2)$ & $2.9(1)$ & $-1.2(2)$ & \multirow[b]{2}{*}{374} & \multirow[b]{2}{*}{3.6} & \multirow[b]{2}{*}{-6.9} \\
\hline $\begin{array}{l}\mathrm{B}^{4}(\mathrm{TO}) \\
\mathrm{B}^{4}(\mathrm{LO})\end{array}$ & $\begin{array}{l}393.7(3) \\
413.1(5)\end{array}$ & $\begin{array}{l}1.23(4) \\
2.35(7)\end{array}$ & $\begin{array}{l}2.6(3) \\
-3.5(5)\end{array}$ & $408.6(5)$ & $1.5(8)$ & $0.2(5)$ & & & \\
\hline $\mathrm{E}^{4}(\mathrm{TO})$ & $428.4(4)$ & $6.11(16)$ & $-11.0(6)$ & $421.9(9)$ & $6.78(16)$ & $-14.2(9)$ & 423 & 6.87 & $-11-10$ \\
\hline $\mathrm{E}^{5}(\mathrm{TO})$ & $443.8(7)$ & $5.33(13)$ & $-8.9(5)$ & $432.7(9)$ & $6.48(14)$ & $-11.0(14)$ & 433 & 6.88 & -12.6 \\
\hline $\mathrm{B}^{5}(\mathrm{TO})$ & $446.0(2)$ & $9.4(2)$ & $-16.6(6)$ & $446.9(8)$ & $8.7(2)$ & $-17.8(14)$ & 449 & 9.31 & -18.7 \\
\hline $\mathrm{B}^{5}(\mathrm{LO})$ & $484.1(2)$ & $7.36(15)$ & $-9.0(4)$ & $500.3(3)$ & $4.75(2)$ & $-1.2(2)$ & 497 & 5.75 & -10.8 \\
\hline $\mathrm{E}^{5}(\mathrm{LO})$ & $488.6(10)$ & $4.70(13)$ & $-8.21(4)$ & & & & 500 & 5.75 & -10.8 \\
\hline
\end{tabular}

${ }^{\mathrm{a}}$ Ref. 11

Table 2. Experimental (exp.) and calculated (th.) Raman-mode frequencies and pressure coefficients at zero pressure as obtained from fits to $\omega=\omega_{0}+\mathrm{aP}+\mathrm{bP}^{2}$. Data of Ref. 11 are also included for comparison. 


\begin{tabular}{|l|l|l|l|l|l|l|}
\hline \hline Mode & $\begin{array}{l}\omega_{0}(\exp .) \\
\left(\mathrm{cm}^{-1}\right)\end{array}$ & $\begin{array}{l}\mathrm{a}(\mathrm{exp} .) \\
\left(\mathrm{cm}^{-1}\right. \\
\left.\mathrm{GPa}^{-1}\right)\end{array}$ & $\begin{array}{l}\mathrm{b}(\exp ) \\
\left(\mathrm{cm}^{-1}\right. \\
\left.\mathrm{GPa}^{-2}\right)\end{array}$ & $\begin{array}{l}\omega_{0} \text { (th.) } \\
\left(\mathrm{cm}^{-1}\right)\end{array}$ & $\begin{array}{l}\mathrm{a}(\text { th. }) \\
\left(\mathrm{cm}^{-1}\right. \\
\left.\mathrm{GPa}^{-1}\right)\end{array}$ & $\begin{array}{l}\text { b (th.) } \\
\left(\mathrm{cm}^{-1}\right. \\
\left.\mathrm{GPa}^{-2}\right)\end{array}$ \\
\hline \hline $\mathrm{T}_{2}$ & $106(2)$ & $0.11(5)$ & $-0.03(4)$ & $96.8(2)$ & $0.77(2)$ & $-0.01(2)$ \\
\hline $\mathrm{E}$ & $206(2)$ & $5.7(3)$ & $-0.22(6)$ & $218.1(4)$ & $2.82(4)$ & $-0.02(2)$ \\
\hline $\mathrm{T}_{2}$ & $281(1)$ & $9.1(5)$ & $0.36(3)$ & $265.7(7)$ & $3.85(7)$ & $-0.05(2)$ \\
\hline $\mathrm{T}_{2}$ & $389(5)$ & $-1.9(2)$ & $0.4(2)$ & $345.1(2)$ & $5.5(2)$ & $-0.11(2)$ \\
\hline $\mathrm{A}_{1}$ & $467(5)$ & $2.0(4)$ & $-0.12(8)$ & $404.3(7)$ & $5.66(8)$ & $-0.05(2)$ \\
\hline
\end{tabular}

Table 3. Experimental (exp.) and theoretical (th.) first-order Raman-mode frequencies and pressure coefficients at zero pressure for spinel-type $\mathrm{CdAl}_{2} \mathrm{~S}_{4}$ as obtained from fits to $\omega=\omega_{0}+$ $\mathrm{aP}+\mathrm{bP}^{2}$. 


\section{AUTHOR INFORMATION}

\section{Corresponding Author}

*Juan Angel Sans Tresserras. Instituto de Diseño para la Fabricación y Producción Automatizada, MALTA Consolider Team, Universitat Politècnica de València. Tel: +34 9638775269. E-mail: juasant2@upv.es

\section{Author Contributions}

The manuscript was written through contributions of all authors. All authors have given approval to the final version of the manuscript.

\section{ACKNOWLEDGMENT}

Financial support from the Spanish Consolider Ingenio 2010 Program (Project No. CSD200700045) is acknowledged. The work was also supported by Spanish MICCIN under projects MAT2010-21270-C04-03/04 and from Vicerrectorado de Investigación de la Universitat Politècnica de València under projects UPV2011-0914 PAID-05-11 and UPV2011-0966 PAID06-11. Supercomputer time has been provided by the Red Española de Supercomputación (RES) and the MALTA cluster. J. A. S. acknowledges Juan de la Cierva fellowship program for his financial support. A. M. and P. R.-H. want to acknowledge to S. Muñoz Rodríguez for providing us with a data parsing application.

\section{ABBREVIATIONS}

XRD, x-ray diffraction; RS, Raman scattering; OVC, ordered-vacancy compounds; DC, Defect Chalcopyrite; DS, Defect Stannite; DR, disordered rocksalt; DZ, disordered zincblende; HP, high pressure; EOS, equation of state; VASP, Vienna ab-initio simulation package; GGA, generalized gradient approximation; PBE, Perdew-Burke-Ernzerhof; PBEsol, Perdew-Burke-Ernzerhof for 
solids; DFT, density functional theory; DFPT, density functional perturbation theory; BZ, Brillouin zone. 
TABLE OF CONTENTS IMAGE

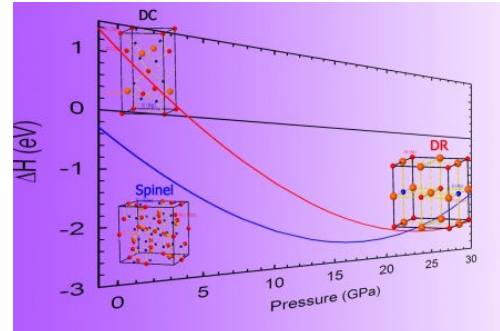

